\title{
Structural Repair on a Composite Aircraft Fuselage Damaged by Fire
}

By

\author{
Christopher D. Cosentino
}

\begin{abstract}
A Report
Presented to Ryerson University

In partial fulfillment of the requirements for the degree of Master of Engineering In the Program of

Aerospace Engineering
\end{abstract}

Toronto, Ontario, Canada, 2014

(C)(Christopher D. Cosentino) 2014 


\section{Author's Declaration for Electronic Submission of a Thesis:}

I hereby declare that I am the sole author of this thesis. This is a true copy of the thesis, including any required final revisions, as accepted by my examiners.

I authorize Ryerson University to lend this thesis to other institutions or individuals for the purpose of scholarly research.

I further authorize Ryerson University to reproduce this thesis by photocopying or by other means, in total or in part, at the request of other institutions or individuals for the purpose of scholarly research.

I understand that my thesis may be made electronically available to the public. 


\title{
Structural Repair on a Composite Aircraft Fuselage Damaged by Fire
}

\author{
Christopher Cosentino \\ Master of Engineering \\ Graduate Program in Aerospace Engineering \\ Ryerson University \\ 2014
}

\section{Abstract}

Composite materials have been used on aircraft for decades with tremendous benefits. Through the use of these advanced materials we have seen a great increase in the aircraft's efficiency, while improving the strength of the aircraft. Unfortunately due to the complexity of this material, it has not been used in large structural components such as the fuselage until very recently. Because of this, there are still some unknown aspects of implementing this material which have not yet been researched. One example that demonstrates this is a large section of an aircraft's composite fuselage structure which has sustained fire damage. The main difficulties here are the unknown extent of damage caused by the fire, the unproven repair methods, and the durability of the repair patch itself. This report outlines some of these challenges as well as offers two different repair methods that are then analyzed using CATIAs FEA suite. 


\section{Acknowledgements}

I would like to take this opportunity to offer my gratitude towards the people I have gained inspiration and support from during this project.

Firstly I would like to thank Dr. Cheung Poon for his continuous wisdom and technical support during the process of completing this project. His help has made this project an invaluable experience that I will carry with me into my career. I would also like to thank my family, for which their constant support through my entire educational career will always be greatly appreciated. 


\section{Table of Contents}

Author's Declaration for Electronic Submission of a Thesis: ................................................................. i

Structural Repair on a Composite Aircraft Fuselage Damaged by Fire................................................... ii

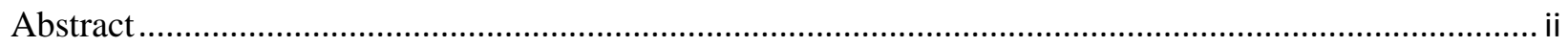

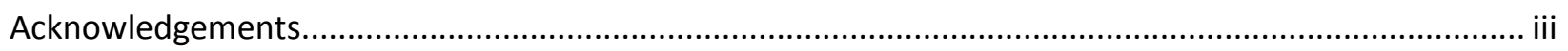

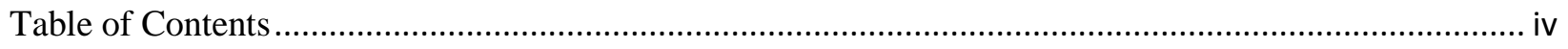

Table of Figures

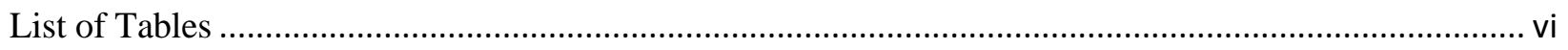

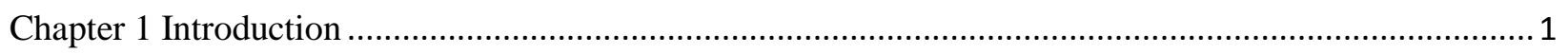

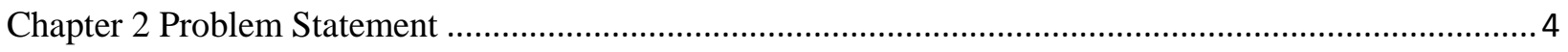

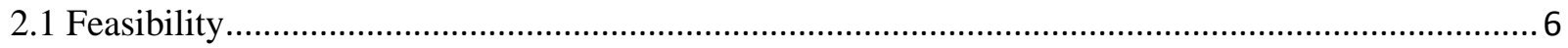

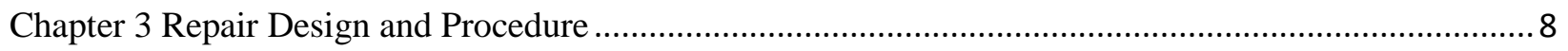

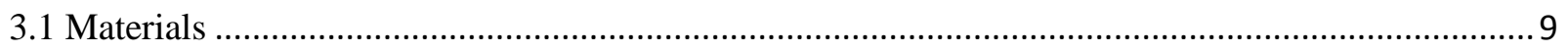

3.1.1 Grid Stiffened Composite Structures (GSCS)...................................................................... 9

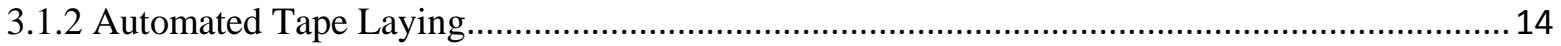

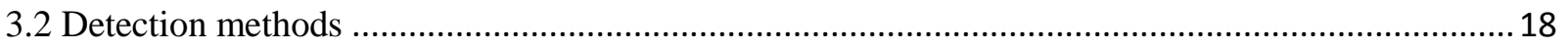

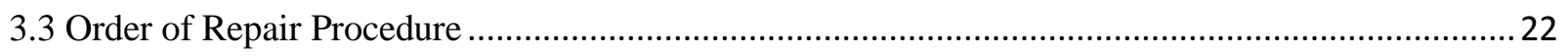

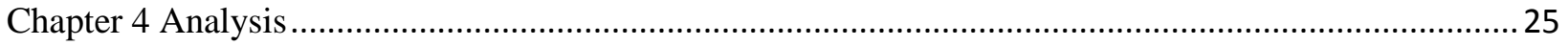

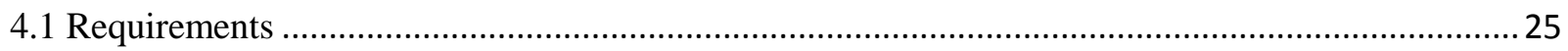

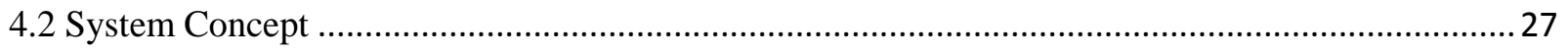

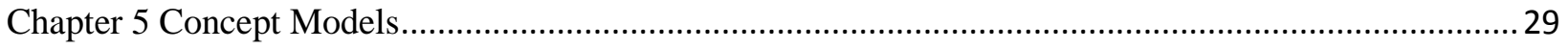

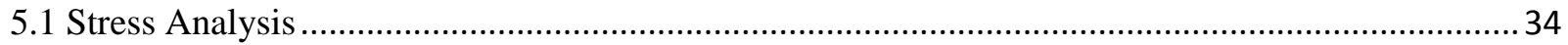

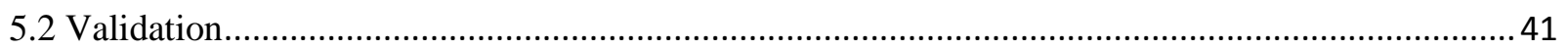

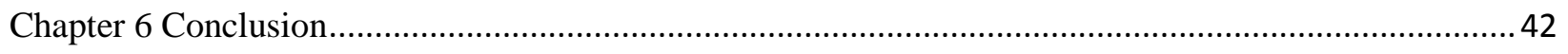

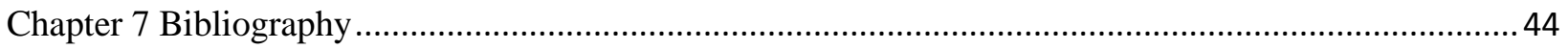




\section{Table of Figures}

Figure 1 - Cross Section of the 787 Fuselage Skin with the Longeron "Mesh" and the Small Ribs[8] .......... 2

Figure 2 - Visible Damage on the 787 Fuselage[11] ........................................................................ 5

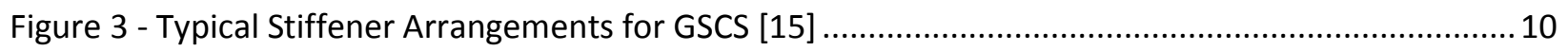

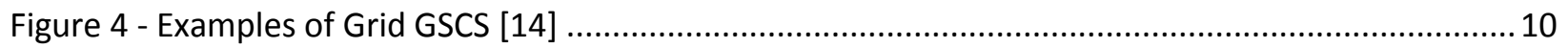

Figure 5 - Stiffness and Strength of Uni-plies Compared to Woven Fabrics[15] ..................................... 11

Figure 6 - Relative Cost of Different Layup Methods Compared to Pultrusion[15]................................. 12

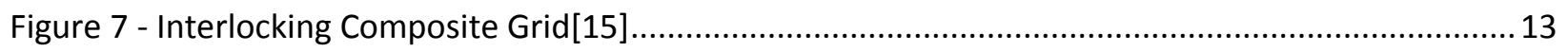

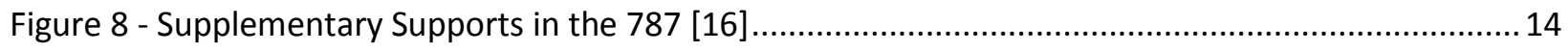

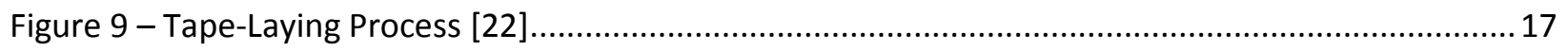

Figure 10 - Dimensions of the Damaged Fuselage Section $(\mathrm{mm})$........................................................ 30

Figure 11 - Interior of the Fuselage Barrel Section Showing the Bonded Patch ....................................... 31

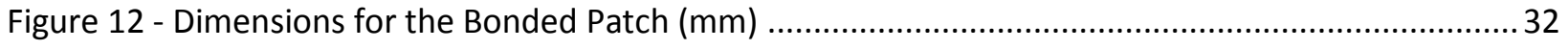

Figure 13 - Fuselage Barrel Interior with the Additional Stringers on the Bolted Repair .......................... 32

Figure 14 - Dimensions for the Additional Stringers $(\mathrm{mm})$................................................................ 33

Figure 15 - Holes used to Lighten and Weaken the Bolted Patch Repair .............................................. 33

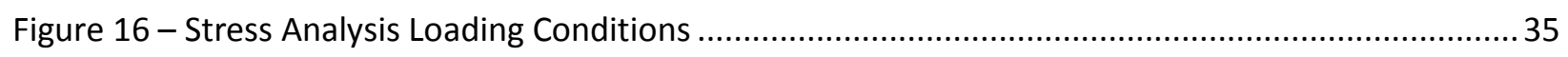

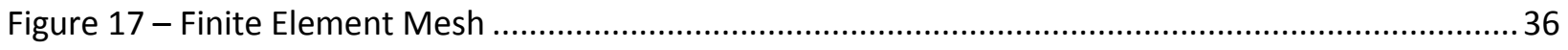

Figure 18 - "Clean" Configuration Stress Analysis............................................................................... 37

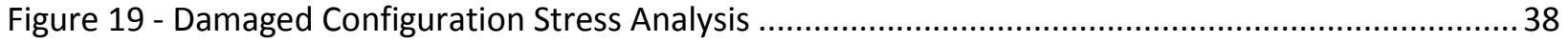

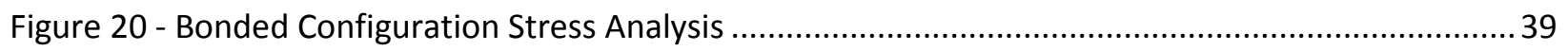

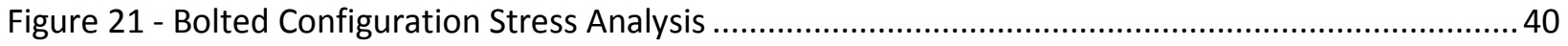




\section{List of Tables}

Table 1 - Weights and Center of Gravity for Each of the Test Models ..................................................... 34

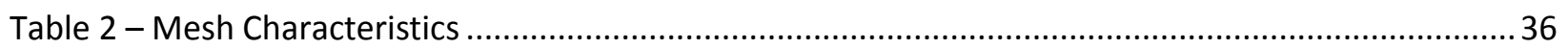




\section{Chapter 1 Introduction}

Composites have been used for decades in aerospace applications to achieve one main goal; to decrease the overall weight of the craft while not sacrificing structural stability [1]. One issue that has plagued these materials since their initial use however is the repair and maintenance of damaged sections [2]. While much research and testing has been done on repairing sections which impact or other physical damage, not much is known on the repair of sections with heat or fire damage [3]. Some of the issues facing this type of repair are the lack of knowledge surrounding the detection of the damaged area due to the fire, and the process in which to repair the damaged section if the damaged section is large.

It is difficult to determine the exact damaged section of a composite structure that has been exposed to direct heat or excessive heat. This is because the damage inflicted on the composite extends beyond the visible damage on the composite itself [3]. When exposed to excessive heat a composite will physically warp or even burn, however beyond this radius of visible damage there is a region of damaged composite where the matrix fiber interface has been weakened and thus must also be replaced [4]. Also, there are not any certifications regarding to this type of damage in order to make identification and repair easier. According to the Federal Aviation Administration (FAA), the Federal Aviation Regulation (FAR) on damage tolerance and fatigue evaluation of structure (23.573) does not discuss the condition of fire damage on a composite structure [5]. 
The other problem with having damage on a large portion of an aircraft fuselage is the replacement of the damaged section. For the purpose of this report the damaged section analyzed will be a large section from the tail section of a automated tape layered composite fuselage structure, similar to that of the Boeing 787 [6]. This structure utilizes a composite grid stiffened automated tape layered composite skin that is reinforced with titanium ribs; see Figure 1 [7].

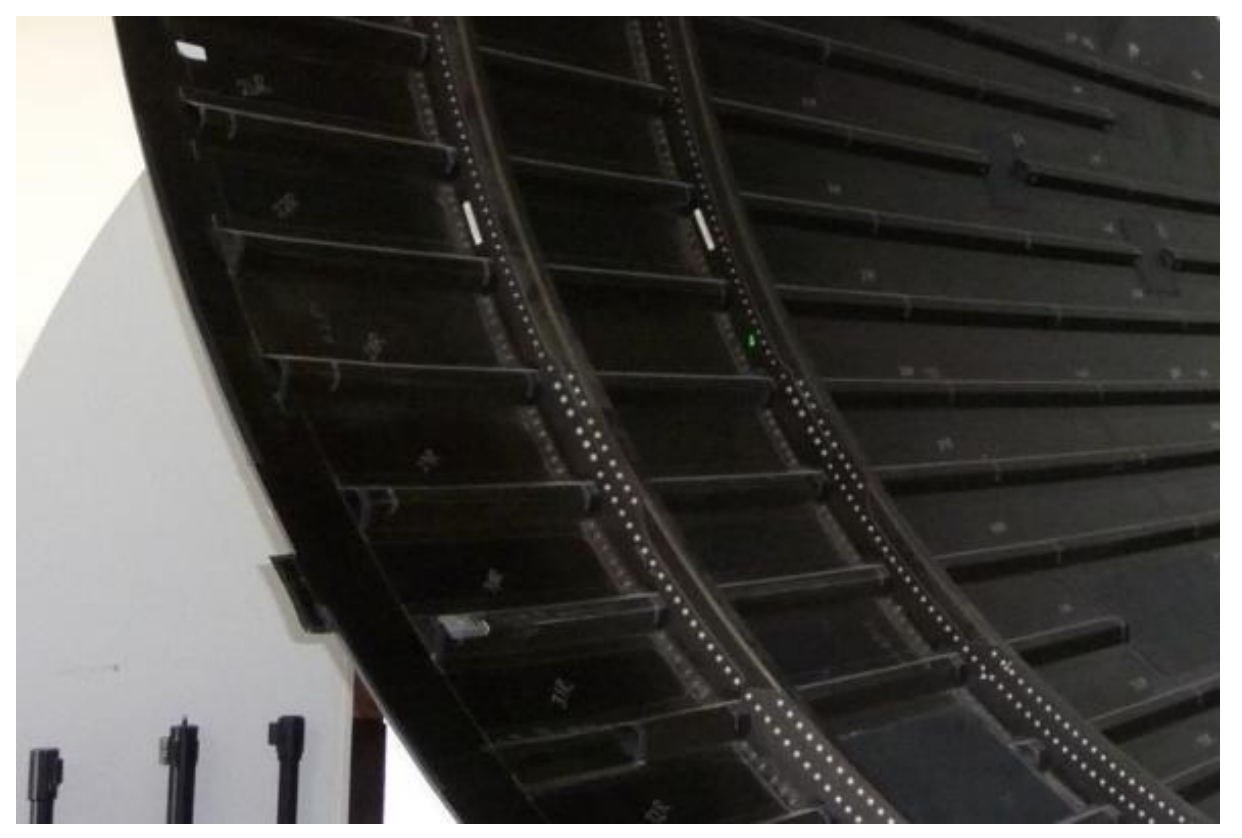

Figure 1 - Cross Section of the 787 Fuselage Skin with the Longeron "Mesh" and the Small Ribs[8]

Specifically the 787 uses a construction that is similar to an older technique called filament winding. This relatively new method of construction is called robotic automated tape laying (ATL) [9]. By using this construction method it means that the fuselage is made up of large onepiece sections. While this configuration has advantages in weight saving and structural stability, it has a disadvantage when it comes to repairing large sections. For small sections of damage that is only a few inches in diameter, the repair procedure consists of simply applying a composite patch to the affected area. For large sections of damage however, since the strength of the continuous fiber has been compromised a bonded plug or flush repair is necessary, in addition to extra structural reinforcements to return the structure to its original strength. While these sections 
will restore the strength of the original system it takes significantly more time that a patch repair or a traditional bolt on repair used on aluminum aircraft today [2]. Also, the repair may require the replacement of major structural reinforcements found in the fuselage and possibly replacing hard points that attach to the vertical and horizontal fins. This is a more complex undertaking because a new section of structure must be attached to the remaining structure which was not damaged and removed. 


\section{Chapter 2 Problem Statement}

This report will cover the potential design process for the design of a repair method that will be employed on a composite fuselage structure that has been damaged from fire or thermal stress. The first thing to do then is to define the parameters of the damages that will be analyzed and repaired. For this, a $5.5 \mathrm{~m}$ long by $1.4 \mathrm{~m}$ wide visibly damaged area will be examined. These dimensions were chosen as it closely resembles a fairly recent incident involving a fire on a 787 that was significant enough to render the aircraft inoperative. The event which happened in July 2013 involved an Ethiopian Airlines 787-8 which caught fire at Heathrow airport. The issue occurred when the batteries in the second emergency locator transmitter caught fire in the aft cabin of the aircraft. According to reports the damage was quite extensive, requiring the replacement of the skin, stringers, and ribs of the fuselage, and even the removal of the vertical

fin in order to reach the affected structures and systems. Also, while the details regarding the repair procedure being completed are being kept a secret, it is known that a complete repair is being performed at Heathrow, rather than a two stage repair where the aircraft would be patched up to make a ferry flight back to headquarters in order to have the entire fuselage barrel replaced [10]. Additionally the issue that has experts pondering the entire incident is exactly how Boeing intends to repair this aircraft. While there are many theories and speculations made about the repair, Boeing remains silent on the technology and techniques used for the final repair, even as of writing this report the aircraft has completed its repair and is set to regain service [6]. 
For this report, the repair of a similar sized damaged section of composite fuselage will be examined. The location of the damage will also be similar to the real world example. The damaged area is located at the top of the tail section, starting at the tip of the tail and extending forward. For a visual example of this damage see Figure 2.

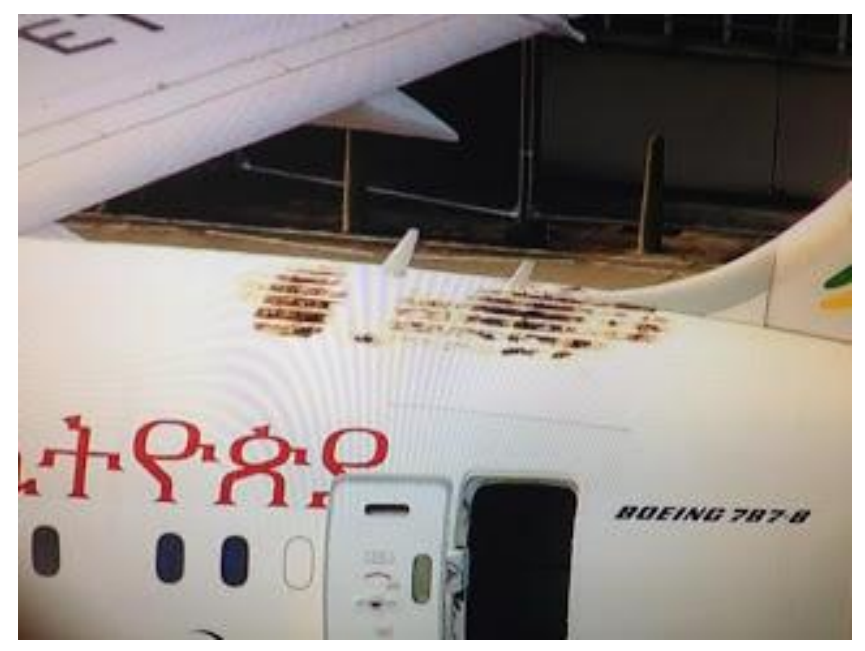

Figure 2 - Visible Damage on the 787 Fuselage[11]

The dimensions and location of the damage are based on a real world repair scenario that a composite aircraft could undergo, however this repair strategy could be applied anywhere a large area of composite fuselage structure, including the internal sub-structure, has been affected by excessive thermal stress. The specified visible damaged area has had full flame burn-through, thus completely compromising the structural integrity of that composite section. The substructure, including the fuselage ribs, has sustained no visible damage. A repair for this damage must be made at the airport where the aircraft is currently stationed. Thus the repair process will only involve the facilities and personnel that are available on site or are able to be flown in by the aircraft manufacturer. 


\subsection{Feasibility}

In order to determine how to approach this problem one must first examine if repairing this type of structure is feasible. Current composite repair knowledge is fairly limited when compared to conventional alloy repair, especially for large load bearing structures. Additionally the effect of heat and fire damage on composites is less known. Also, currently there is no industry standard that outlines how to go about properly examining a burned composite structure or how to repair it if the damage affects the structure. However, with the knowledge gained from repairing previous aircraft and other structures, there are various methods and materials that can be applied to create a valid solution [12]. Because of these unknowns the feasibility analysis will have to be kept to very high level and will be mainly a conceptual theory on the possibility of certain aspects of the repair.

Firstly the facility will be analyzed. If an aircraft receives physical damage at an airport, or is able to make a safe landing at an airport after damage, there are usually facilities on site capable of housing the aircraft as well as accommodating repair equipment. These facilities are usually capable of conducting structural damage repair that doesn't involve replacing a component as large as a whole wing, for example. If such a repair is required, it is usually left to the original equipment manufacturer (OEM) of the aircraft to send its own equipment and personnel to the airport in order to rectify the issue [13]. With this in mind the most ideal repair for this fire damage example, which is repairing the whole barrel section, is not possible. 
This then suggests that a repair of the structure and skin of the damaged section only must be undertaken. While these repairs have been done on metal structures, and there are several theories on how to complete the repairs on composite structures, none have yet been proven. Most notably the extent of structural integrity loss due to the heat damage itself has no standard way of being analyzed. Currently there are theories of using certain types of non-destructive testing methods such as ultrasound to find impurities in the structure, however there is no certified benchmark relating certain types or strengths of heat to a certain damage level [3]. Thus a conservative estimate for the affected area must be taken, which involves cutting a larger section of the aircraft around the visibly damaged area to ensure the structural safety. 


\section{Chapter 3 Repair Design and Procedure}

This section will describe the different technologies, materials, manufacturing procedures, as well as the detection methods and procedures used to complete the repair. There are a wide variety of different methods for the detection of the damaged area; each has its own benefits when it comes to the detection of damaged fiber reinforced composite materials. These methods can also be more effective when used together in order to obtain a more accurate result and a more precise repair of the damaged area. The various manufacturing methods of different composite structures also have their own benefits which will be discussed. This section is crucial to the final result and conclusion of the report as is outlines the current knowledge surrounding the detection of damage on composites as well as their manufacturing methods and structure types. There is a caveat to this however; very little is currently known about these composite structures and their manufacturing processes. This is due mainly to how new and complex the whole phenomenon is, and because of this companies keep information such as layup procedures and material properties as a closely guarded secret. Secondly in terms of detection methods, while there have been some theoretical advances into the potential detection of fire damage on composite structures, the accuracy as to exactly where the damage is on the structure and what its extent is has yet to be proven. Lastly there is the repair procedure itself. This will incorporate the materials and detection method as well as the general facilities needed in order to complete the repair and the order in which to do it. Thus the review in this section will be that of a highlevel of detail regarding the materials, detection and repair procedure. 


\subsection{Materials}

While fiber composite materials have been implemented on aircraft for many years now, it has only been recently that they have been used in such a large portion of the aircraft structure. This has been due to the advancement in new composite manufacturing methods and configurations. These advances come in the form of two main configurations, automated tape layered composites and grid stiffened composite structures. These two types are not exclusive though, and in fact are most effective when combined into one application. By doing this the structure receives the strength benefits of both configurations [14]. Firstly the concept of grid stiffened structures and panels will be discussed with the different manufacturing methods and attributes. Then the concept of automated tape layered will be discussed as well as its implementation in conjunction with the grid stiffened composites.

\subsubsection{Grid Stiffened Composite Structures (GSCS)}

A grid stiffened composite structure or GSCS, is any structure that is reinforced by a series of longitudinal and lateral stiffeners that are made out of any type of fiber reinforced plastic composite. By doing this a lattice structure is created which is exceptional at resisting higher loads of bending and twisting moments. This design could incorporate anything from a simple crisscross pattern of stiffeners intersecting at $90^{\circ}$ of each other, to a complex multilayered honeycomb structure. Generally however, a typical GSCS will consist of an outer shell, which in this case would be the aircraft skin, which will be supported by the grid of stiffeners underneath. These stiffeners would typically only run in 2 to 4 different directions which can be seen in Figure 3 [14]. 

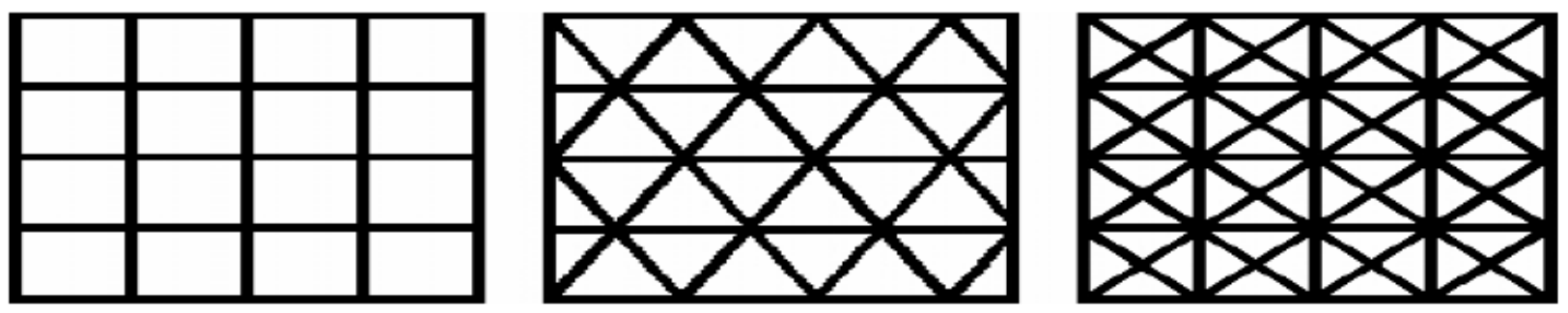

Figure 3 - Typical Stiffener Arrangements for GSCS [15]

While a 2 directional grid is the most cost effective, a 4 directional grid has superior structural rigidify in more loading scenarios such as twisting moments. Figure 4 shows different examples of simple GSCS.
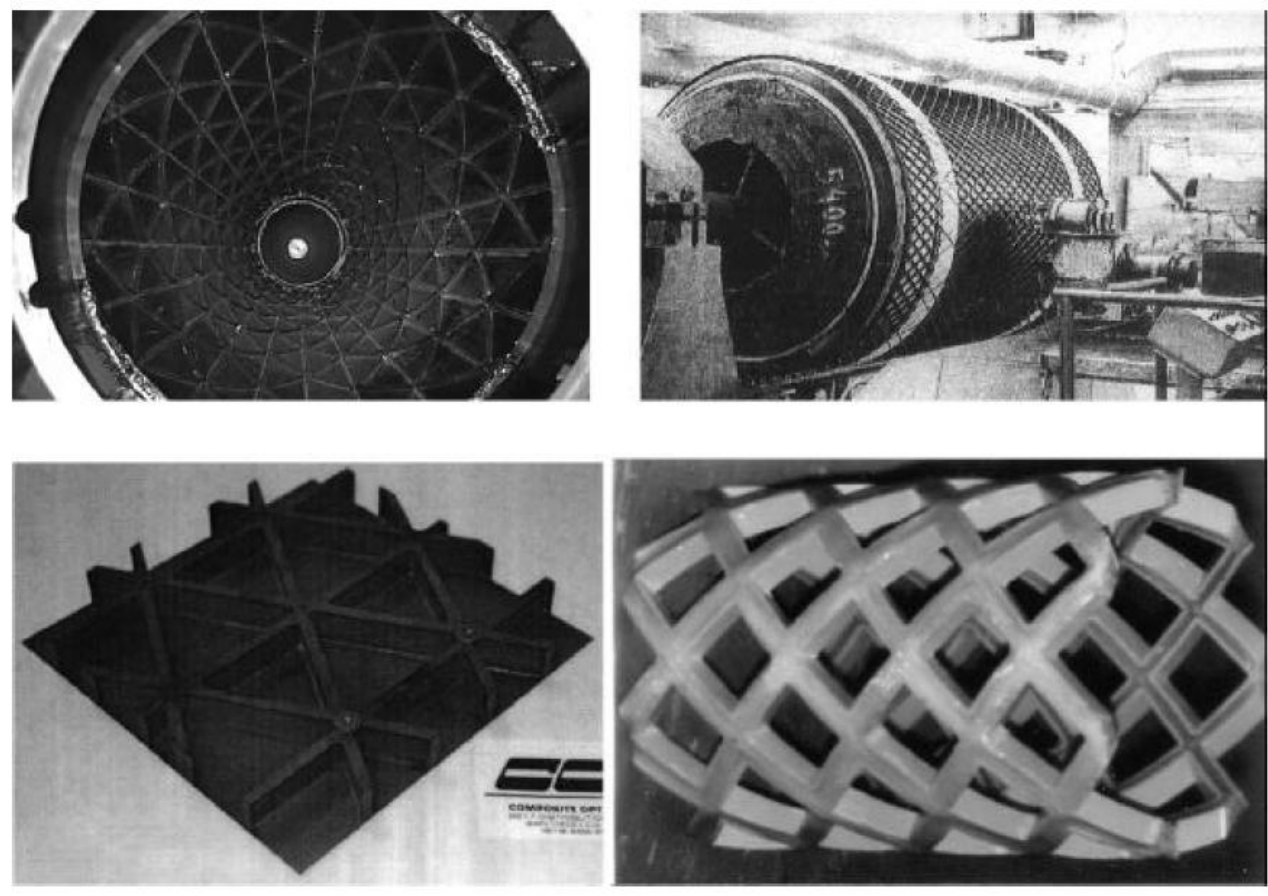

Figure 4 - Examples of Grid GSCS [14]

These stiffeners are generally made out of unidirectional, uni-ply pultruded composites structures, meaning the fibers are all aligned along the length of the stiffener itself. By doing this, the all around strength and stiffness of the structure increases, however there are more benefits of unidirectional GSCS over a traditional multi directional or woven fabric, multilayered composite 
panels. For example due to the material mismatch, laminated woven fabrics tend to be more susceptible to delaminating and micro-cracking when compared to uni-ply GSCS which is generally more robust in this case due to the uni-ply characteristic, as well as the damage mitigation inherent in the grid design. Once a crack has formed on the outer shell it is easily contained within the affected grid cell and is restricted from propagating further. This causes them to have lower impact and fatigue resistance. Additionally the GSCS tend to have higher flexural rigidity and are less susceptible to moisture incursion to their open nature which lends to better ventilation over sandwiched panels. The one drawback of the GSCS however is that the entire structure itself is much thicker than the multiply for the same amount of material [15]. Figure 5 compares the general material properties of stiffness and tensile strength of both the uni-ply and woven fabric composites.

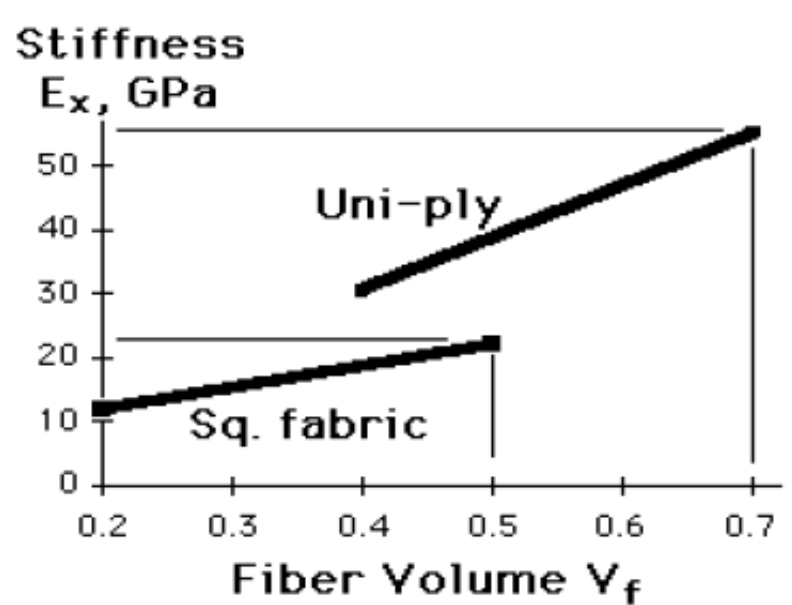

Figure 5 - Stiffness and Strength of Uni-plies Compared to Woven Fabrics[15]

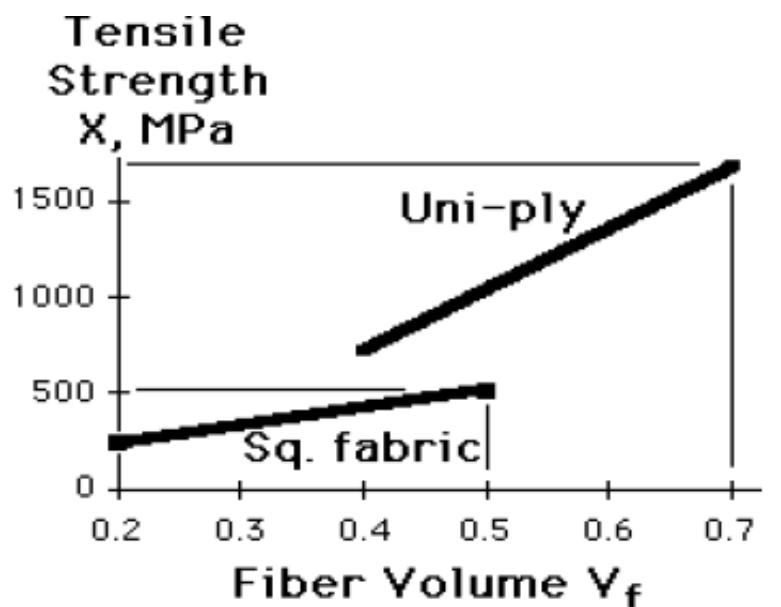

Fiber Volume $V_{f}$

These materials take full advantage of the benefits of composite materials, such as their relatively light weight, stiffness, fatigue durability, and increase their maximum supported load by adding additional structural support. Due to the fact that they are so strong and light, these structures are also quickly becoming more and more cost effective for an increasing number of applications. One of the factors that make this type of composite structure more inexpensive is 
the automated low-cost manufacturing. This automated, single cure process is superior to the conventional skin construction consisting of stringer and skin sandwich bonding, which requires costly and time consuming hand layup operations. This benefit tends to be superior when constructing cylindrical or conical structures, which directly related to aircraft structures [14]. Ultimately an automated pultrusion method is seen as the most beneficial in terms of manufacturing as is the most cost effective. Figure 6 shows the comparison of the relative cost between pultrusion and other composite layup methods [15].

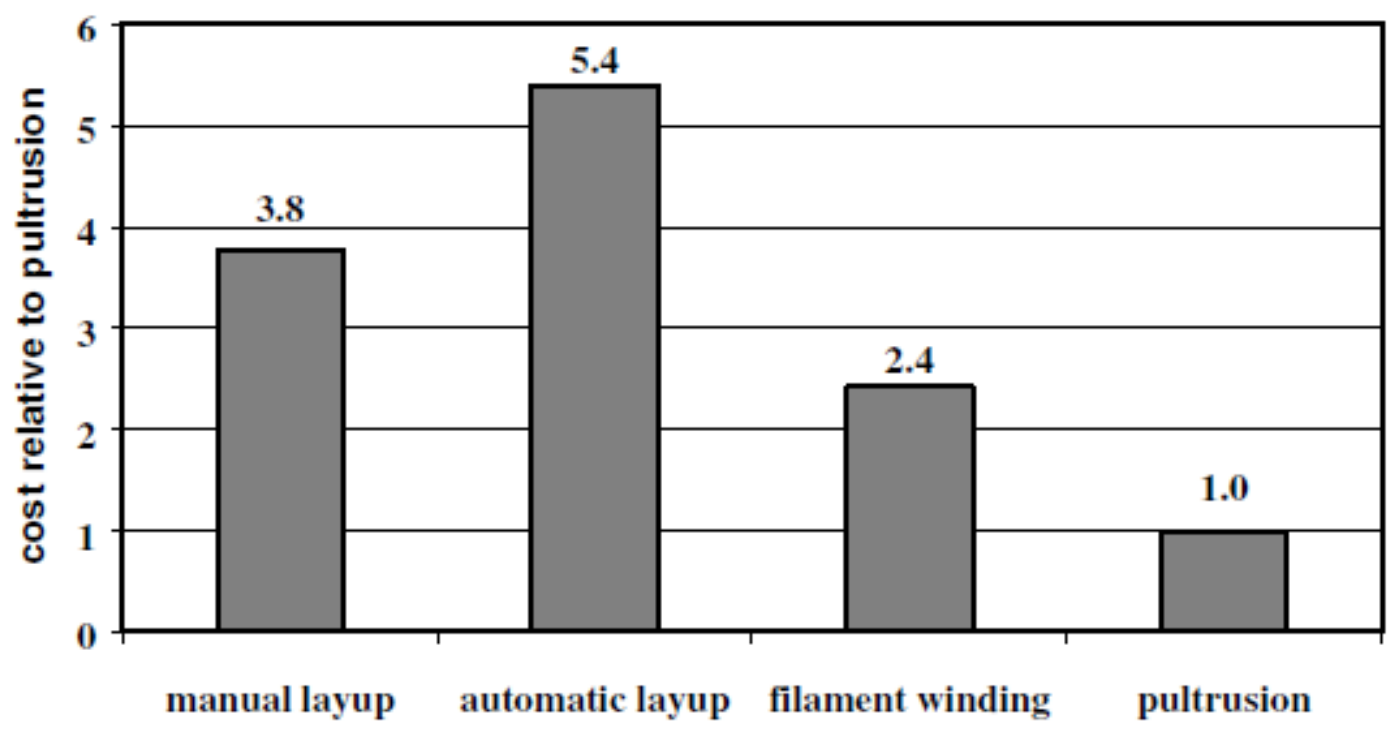

Figure 6 - Relative Cost of Different Layup Methods Compared to Pultrusion[15]

These composite grid structures are not without their drawbacks however. As mentioned earlier these structures, while ultimately stronger require thicker geometries for the same amount of material used in a traditional sandwich structure. While the manufacture of the grid pieces itself using automated pultrusion is more cost effective, the assembly of the grid an installation onto a fuselage structure can be rather costly in terms of money and time. Also, even though they have been researched for the past couple decades, these composite structures are still relatively unproven and have gaps in knowledge of their behavior, specifically in the case of failure 
behavior [14]. Additionally, the method most used to connect intersection of the grids is an interlocking method, where notches are cut out of the stringers so they can fit together. The problem here is that at the node points where the reinforcements connect are weak points and need to be reinforced [15]. Figure 7 shows a simple example of the interlocking structure and cap reinforcements. Because of these drawbacks there have been little practical large scale applications to utilize this type of composite structure in full service.

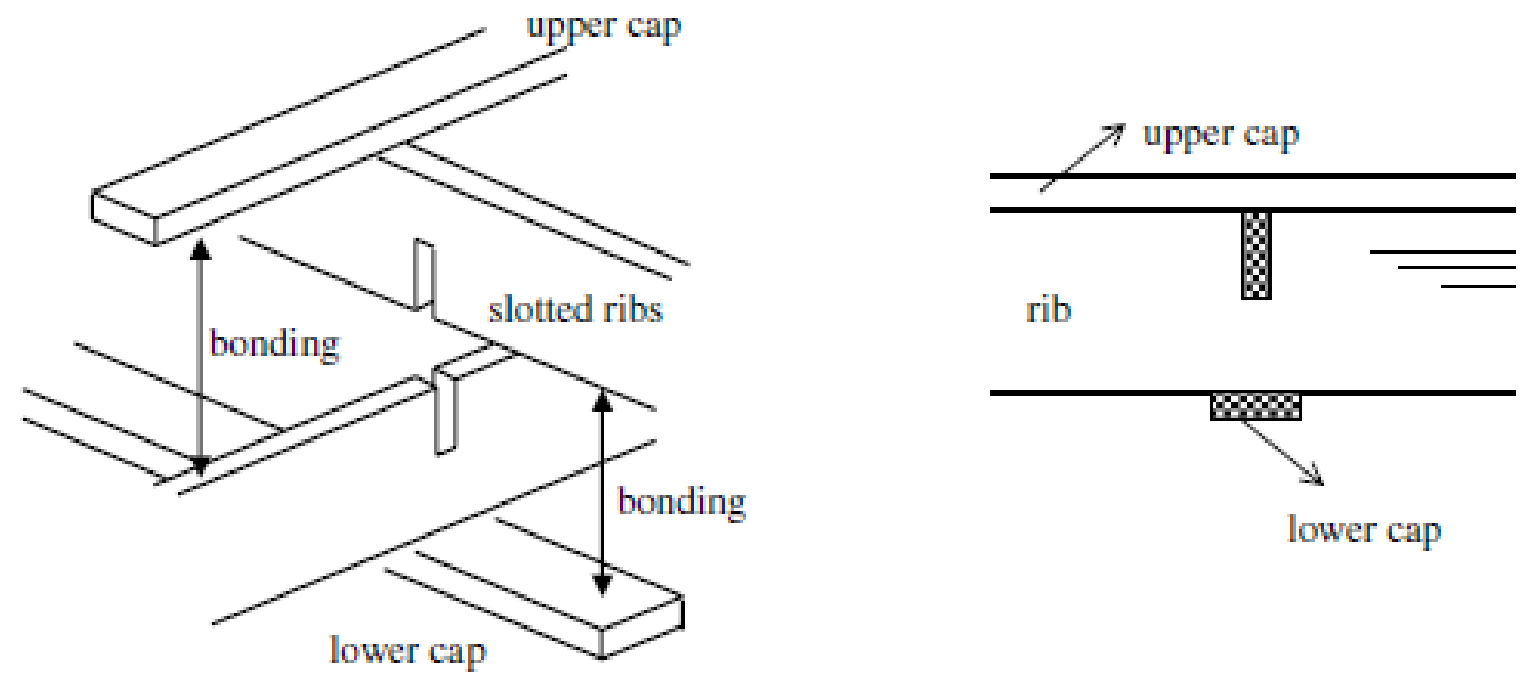

Figure 7 - Interlocking Composite Grid[15]

Relating this back to the project, this is the type of composite that is on the current damaged structure. The 787 composite fuselage utilizes a 2 directional composite grid structure with a composite skin. In this application rather than having a diamond shape grid along the length of the fuselage, the 787 utilizes long straight stringers with circular ribs that wrap around the inside of the fuselage. While the stringers are bonded to the skin, the interlocking ribs are bolted, and then bonded to the stringers. This configuration is standard for aircraft fuselage systems incorporating more conventional metal materials as it is optimal for the specific types of loading that an aircraft undergoes. The main different characteristics that are different with the 787 composite grid is the non continuous stringer formation, and the ATL of the fuselage barrels. 
Additionally, as seen in Figure 8 the 787 is equipped with supplementary supports consisting of metal cross-members and metal ribs.

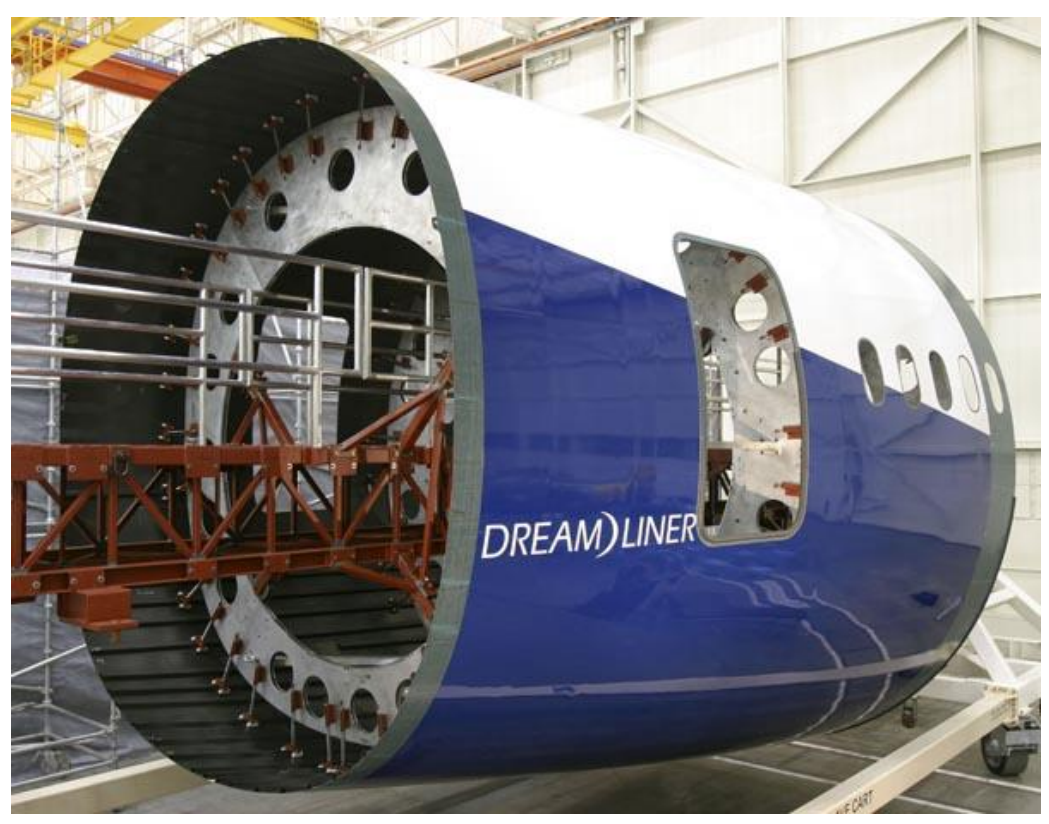

Figure 8 - Supplementary Supports in the 787 [16]

\subsubsection{Automated Tape Laying}

Since the topic of automated tape laying (ATL) is rather complex both in manufacturing and material properties, a brief introduction into these topics as well as potential applications relating to this type of material will be discussed in this sub-section. In order to understand the fully automated ATL process a similar method, filament winding, will be discussed first [17].

The process of filament winding can be simply explained as winding a single strand of material over a form to create a shell structure. More specifically in terms of composite materials it is the process in which a single strand of composite fiber and resin is wound over a shape. The shape that the fibers are wound over is called the mandrel. The process in which this happens is that a spool of the fiber is drawn through a pool of resin. The fiber in this case is a carbon fiber; 
however other types of fibers can include glass, jute, sisal, cotton and other synthetic fibers. The resins used are usually epoxies, while polyesters acrylics and others can also be used. A specific resin and fiber combination must be used in order to attain the maximum adhesion between the fibers and the epoxy. Other factors considered in the winding process are the winding speed, the fiber tension, fiber to resin ratio and the fiber orientation pattern. All of these factors will have consequences on the structural behavior of the final structure. The wet wound structure once finished and the number of desired wound layers is complete, is put into a curing oven in order to harden and ultimately bring the shell to its full strength [18]. It is also unique in the realm of composite construction as well due to the layup not being one layer or one layer at a time [19].

This manufacturing method is best used in the construction of cylindrical and conical structures, due to the consistent geometry, which is easier for the filament spool and mandrel actions. These are not the only types of structures that can be made however, as many complex shapes can also be made using this method. The cylindrical shape is of most interest however as that is the general shape of the vast majority of conventional commercial aircraft fuselage structures. This manufacturing method has recently started to gain acceptance in aerospace applications mainly due to their reliability and mass efficiency. This is mainly due to the unidirectional nature of the winding. Another benefit of this type of material manufacturing is something that is referred to as self stabilization, which makes these structures highly immune to manufacturing and testing imperfections as well as giving the structure very high resistance to buckling per weight of material. This method can also be used to create the ribs and stringers of a fuselages internal composite grid structure, which as discussed before adds significant strength and rigidity to the composite shell. By integrating the shell and grid structure into one continuous structure this process also takes advantage of the materials most notable benefit; the continuous 
fiber. Since the entire composition shares the same fiber, even through the grid structure of rib and stringer reinforcements, the entire fuselage has a potential for excellent load distribution as the stresses are shared seamlessly with the rest of the structure [20].

The 787 utilizes a continuous carbon fiber reinforced polymer structure in its main fuselage design, and Boeing has been researching both GSCS and ATL for over a decade [21]. Based on this research Boeing utilizes a type of filament winding called robotic automated tapelaying on its fuselage structures [9]. ATL is very similar to filament winding in that both process involve protruding continuous fibers that are pre-impregnated with epoxy over a mandrel or shape and then will need to be cured in a curing oven. This will result in a similar structure with similar physical attributes as filament winding. ATL is much more complex than filament winding however, as there can be several printing heads used to protrude several strands at the same time resulting in a tape laying process. Using this method much more complex geometries can be constructed with more accuracy and complexity in fiber orientation as well. Using this process it is also not necessary to construct only cylindrical structures. Since each "spindle" essentially prints the material onto the surface, non continuous mandrels, such as a complete round cylinders or barrels, can be used to print on. This opens up countless possibilities where this fully automated process can very accurately print a complete composite structure. This process can also be relatively quicker than filament winding [17]. Figure 9 describes the specific process Boeing takes to manufacture the 787 fuselage using the tape laying method. 


\section{How Boeing makes a composite fuselage}

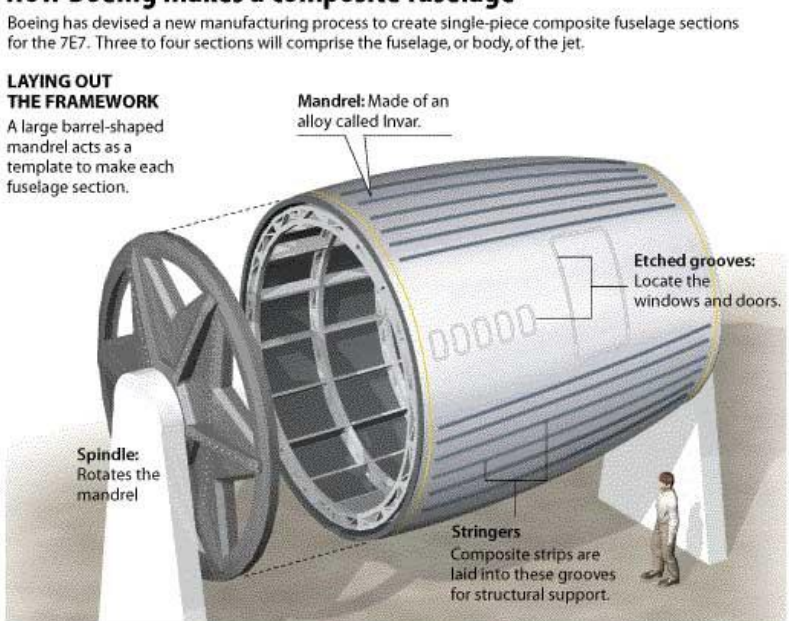

WRAPPING THE FUSELAGE

Up to eight robotic tape heads apply multiple layers of

composite material to the

spinning mandrel,

creating the fuselage

skin.

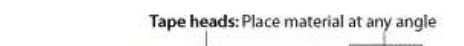

CURING AND HARDENING

The composite-covered mandrel is

rolled into a giant kiln, called an

autoclave, where it is baked for hours

at up to 250 degrees.

Mandrel and

fuselage section
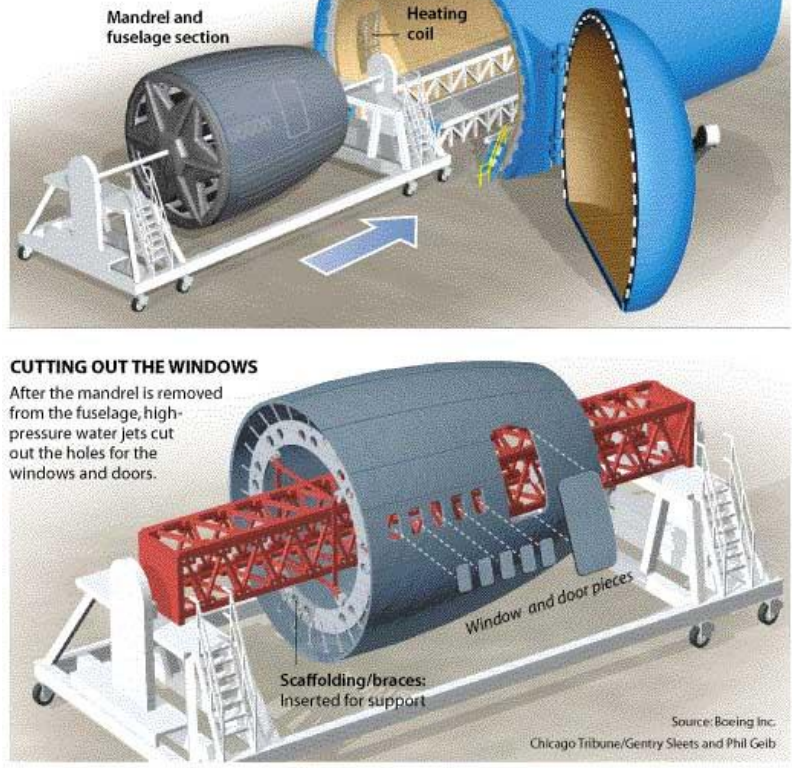

Figure 9 - Tape-Laying Process [22] 
It is unclear now however, as to what extent Boeing has researched the damage tolerances and behavior of these structures. As of now there has been little research completed on the behavior of damages of these composite structures. Thus there are quite a few unknowns as to the real world implemented procedures for detection and repair of damaged composite fuselage structures, especially for fire related damage. This information is still proprietary and has yet to reach the public domain in order to retain the competitive advantage over the competition. It is clear however that Boeing has researched this topic and has more working knowledge of these types of materials due to that fact that have implemented it on the entirety of their next generation commuter jet fuselage.

\subsection{Detection methods}

Previously in this section there has been mention of the benefits of these new advanced material configurations, however, there has also been some concerns brought up regarding the knowledge surrounding damage behavior of composites. Specifically with the recent large scale adoption of fiber composite structures on aircraft many questions begin to arise as to the thermal degradation of material. It is known, however, that composites are more susceptible to heat and ultraviolet light than conventional metal structures. Specifically it has been seen that these material begin to show signs of fatigue when exposed to these phenomena. It has been found through preliminary research that long exposure to heat and UV light break down the composite structure by setting off a series of chemical reactions such as oxidation. Heat stress due to lightning strikes and engine overheating or failures also can result in the degradation of the matrix which could lead to complete mechanical strength failure, or even cause the composite to become brittle and ultimately crack [23]. Additionally there has been little research completed on the performance of fiber composite materials that have been exposed to excessively high 
temperatures of around $2000^{\mathrm{O}} \mathrm{F}$ for a few seconds. This scenario would be directly related to that of a fire that the composite material [3]. Like the problem scenario that this report examines this could be due to a fire caused by a malfunction, such as a battery fire or an engine fire, or it could be the result of something more drastic such as a crash scenario. While these scenarios are not all too common it is always necessary to prepare for these scenarios and their ensuing consequences especially with aircraft.

With the growing adoption of these composite materials in the aerospace industry it is becoming even more imperative that an accurate method for detection can be implemented in case a composite structure experiences damage of any kind. There are currently a few different methods being researched and proven to more accurately determine the severity and position of the damaged composite section [23]. These methods include a simple visual inspection, as well as complex UV fluorescence (UVF), laser induced fluorescence (LIF), ultrasonic, Fourier transform infrared (FTIR) spectroscopy and thermography scanning techniques [24]. While only useful in certain scenarios, a simple visual inspection is always a good precautionary step to take and could lead to finding a damaged section between routine maintenance intervals where more precise equipment can be used [3]. For example, when a carbon/epoxy composite structure has been exposed to temperatures of $550^{\circ} \mathrm{F}$ and above it can start showing evidence of cracking and surface blistering. At this temperature however there is also sub-surface damage and imperfections that can occur such as disbanding and delaminating, which is why it is imperative to utilize other non-destructive evaluation, testing, or inspection (NDE, NDT, NDI) methods to make a more accurate conclusion as to the extent of the damage [23]. 
The other types of detections operate on the same basic principle; the material is exposed to a certain wavelength of light or other type of electromagnetic (EM) radiation, then sensors are put in place to detect and record the ensuing radiation or light given off by the effect. Specifically the UV and laser induced fluorescence operate on the principle that exposing the material to UV or laser radiation, which in turn excites the molecules of the test area. After a short period of time, usually a few microseconds or less, the molecules release the energy imparted by the light source [25]. Depending on the different material properties and configurations a different wavelength is emitted after the specimen is excited. Through extensive physical testing of the material afterwards a correlation can be obtained between the different wavelengths given off and the type area and extent of physical degradation of a material after it has been exposed to thermal stress. Through this it has been found that while UV fluorescence has been seen to provide a more qualitative means of assessing the thermal damage, laser induced fluorescence was capable of presenting more accurate qualitative assessment of the damaged section. Thus the LIF method, once calibrated to the material, is seen to be able to assess the material property degradation and depth of the thermal damage [3].

The use of FTIR has also recently been used to measure the imperfections in composites with positive results. This complex process is based on the infrared spectroscopy in which infrared radiation at different wavelengths is projected onto the test material. As the radiation passes through the material a signal is given off, which is digitally recorded. This data is then processed by a Fourier transform technique and a result can then be obtained. Using this method it is possible to scan large areas of a composite material and determine if damage has occurred or not. Even further, when properly calibrated this process can also determine the temperature at which the composite was exposed to, giving maintenance crews a more accurate picture as to the 
extent of the damage sustained by the structure. In modern applications the use of a hand-held apparatus can be deployed in order to make field detection more practical [23]. Additionally recent research is starting to show that once calibrated this method could also prove to accurately predict material properties [3].

Ultrasonic or C-scanning techniques are another useful technique that can be employed in the field to detect thermal composite damage. This method utilizes the same method currently used in the medical field, which consists of taking advantage of ultrasonic imaging in order to penetrate a material and take a $2 \mathrm{D}$ or $3 \mathrm{D}$ image of the test section. This type of detection is seen to be advantageous at determining the existence of different types of damage ranging from disbands and delimitations to foreign object inclusions and impact damage of the composite structure [24]. This method however is very subjective as to determining the extent of damage to the material properties of the specimen and thus is more suited to the imaging and qualitative analysis of the damaged structure [3].

The final main scanning and detection technique that is currently being researched to determine damage on composite structures is thermography scanning. Like ultrasonic testing thermography is capable of detecting disbands, delimitations, foreign object inclusions and impact damage, however it is more accurate [24]. Pulsed thermography operates by exposing the surface of the sample with a uniform pulse of light usually from a xenon flash lamp array. This pulse usually only lasts a few milliseconds. Then and IR camera monitors the response of the thermal pulse to the surface of the material. This type of thermography works well for surface imperfections or thinner structures [26]. For thicker structures and to get a deeper image lock-in thermography can be used. This method takes advantage halogen lamps, ultrasound or even 
mechanical stimulation in place of the xenon lamp. The rest of the procedure stays the same, which is the IR camera captures the response of the material for the duration of the process [27].

While each of these methods has their own individual strengths and weaknesses, it has been seen that they are all valuable in the detection of damage caused by thermal stress on composite materials. However, even though some of them have been around for decades they are all relatively new processes in the realm of composite damage detection. Because of this there need to be more research done with them on different types of composites in different configurations. If this can be accomplished, and these methods are all used in concert to determine the properties of a damaged composite material, the accuracy of thermal stress damage detection on composite materials can be significantly increased.

\subsection{Order of Repair Procedure}

The previous two subsections have discussed the possible new technologies used to construct composite structures and detect the area of damage and the severity to which the structure has been compromised. Now the next step is to go over the potential repair procedure of the damaged composite section. The very first step in this process is the detection of the damaged section. In the scenario of a large scale fire the first thing that will happen after the fire has been put out is a visual inspection to assess the severity and scale of the visible damage. At this point an initial prediction can be made as to damage the aircraft has sustained and the aircraft can be moved to a section of the airport for further repair. Once moved, structures such as scaffolding can be set up in order to more easily work on the damaged area. Then using the non-destructive evaluation (NDE) methods mentioned above a determination can be made as to how much damage the aircraft has indeed sustained, including the area and material degradation. 
Also from the NDEs and other data recorders onboard the aircraft some conclusions can be made about the initial cause of the fire, which will prove useful to prevent the accident from occurring again. The next step would be to remove the examined area that was determined to be structurally compromised. This could be done most easily by simply cutting the area of damaged section out and lifting it off of the fuselage itself.

The next and most challenging step would be the repair itself. Since the facilities at an airport are not suited to replace a large section of the fuselage barrel, a patch will need to be constructed offsite, shipped to the airport and installed on the airframe. This installation, previous to being shipped and installed, must be carefully engineered in order to sustain the loads of a permanent service life or at least a ferry flight to a facility where a permanent fix can be made. Once the patch has been designed, a repair procedure must be completed in a specific order. Depending on the type of the specific procedure will be different, for example a bonded verses a bolted repair; however the basic operation will be the same. Firstly the new ribs will need to be installed. These will need to be attached to the existing airframe to the skin alone by using a full circular rib. This method would involve the fully replacing the existing ribs that needed to be cut in order to remove the damaged material. The second option would be to attach semicircular ribs to the still intact existing ribs which would span the gap between the rib sections that had to be removed. After this step is taken the outer shell or skin would be installed in order to have the airframe regain its aerodynamic shape. The installed patch itself would have to be designed such that it could seamlessly transfer loads experienced by the airframe without a buildup of stress concentrations. 
The final step is re-entering the aircraft into full time service. In order to do this however the aircraft will need to be recertified by the necessary regulatory organizations. While the aircraft was originally certified to fly, it will need to be certified again to prove its airworthiness. This is due to the fact that the airframe has undergone a significant change in configuration and structure. This certification will not be as long or as intensive as the original tests required to prove the aircrafts capabilities for the first time, however they will need to be able to prove that the new modifications will not compromise the original intended structural capabilities of the airframe. Depending on the repair configuration performed the certification testing time could vary. 


\section{Chapter 4 Analysis}

In order to come up with a solution for this problem a system concept must be created that sufficiently outlines the process in which to fix the damage, either permanently, or a temporary fix that will hold until a permanent fix can be made at a later location. This temporary fix would involve over-engineering the patch so it will hold until the aircraft can be flown back to the original manufacturing plant in order to retrofit it with completely new, unmodified, fuselage sections. This would ensure the final repaired aircraft could resume service unmodified from the original. A permanent fix would reenter service with the patch structure remaining for the rest of the service life. A system needs to be created that firstly detects the damaged area. Then once the damaged area is removed a replacement structure and repair process must be designed and implemented. To achieve all of these goals however, a specific list of requirements needs to be completed.

\subsection{Requirements}

The main requirement of this repair is to be able to structurally reinforce the large area that has been affected. From here the repair has 2 different requirements depending on which scenario is chosen. The first, which will be called the bolted temporary repair strategy (BTRS), consists of creating a temporary patch for the damaged area. This method is basically a brute force method to solve the repair problem. Less time will be taken on determining the specific damaged area and the necessary loads for the sustained life of the patch. Instead a section will be cut out that extends well beyond the visible affected area, and the reinforcements will be over designed. This will be done to ensure the guaranteed structural stability of the repair, considering 
the multitude of unknowns in both the detection of the damage as well as the repair of this configuration. By doing this the aircraft might be unbalanced by the added weight and will need re-balanced with ballasts. This will be for one flight only however, because this scenario's ultimate goal is just to get back to the manufacturer's construction facility. Once there the entire fuselage will be remade and replace the damaged barrel. Once completed the aircraft is restored to factory specs.

The second scenario, the bonded permanent repair strategy (BPRS), consists of creating a patch repair for the aircraft that is permanent, which means that it will remain on the aircraft for the rest of its service life. In doing this there needs to be a lot more attention spent on determining the exact damaged area and a thorough knowledge relating to aircraft lifecycle This includes consideration for fatigue loading of the repair over the next 20 to 30 years the aircraft would be expected to remain in service. However due to the inherent nature of this type of composite structure, in order to repair the fuselage with enough strength to resist these forces some amount of weight will be added to the aircraft and will have to be accounted for.

Another important requirement is cost. While this is not the primary objective, the cost will definitely drive the decision for different materials and ultimately will determine which repair scenario should be implemented. 


\subsection{System Concept}

From the analysis a general system concept can now be created. Based on the feasibility study there are 2 distinct system concepts. The components of each will be examined and the process for the distinct processes will be outlined.

Both system concepts begin with examination and detection of the damaged area. This is done using non-destructive evaluation (NDI) methods such as a simple visual inspection, as well as ultrasonic, UV, Fourier transform mid-infrared (FTIR) and laser induced fluorescence (LIF) tests.[3] These tests would not only have to be completed on the skin structure but also on the fuselage ribs. After the damaged area has been successfully determined it must be removed by carefully cutting out the required section of ribs and skin. It should be noted here that there is a possibility that the substructure will not be damaged to any significant margin. If this is the case, the replacement of this structure will not have to be performed, decreasing the difficulty, time and cost related to the repair. Now from here two distinct design concepts emerge. These are based on the BTRS and BPRS concepts stated in the feasibility analysis portion.

In the first repair scenario (BTRS) a temporary patch will be installed. This will be a bolted composite mesh patch with reinforced ribs. Similar to the existing skin structure a composite mesh is a composite skin structure that incorporates the outer skin with an internal bonded composite structural that provides the longitudinal rigidity of the aircraft. Also this type of composite structure as well as bolting it instead of bonding it to the fuselage is more conventional thus both time and cost for repair would be fairly low. This mesh will then be attached to the new fuselage ribs that are installed and bolted on the remaining undamaged rib 
structure. The new rib structure will be made out of the same material as the current structure and will be bolted on to the excising ribs by using a sort of splint brace design. Due to the added weight of both the bolded mesh and the reinforced ribs this design, the aircraft would have to be rebalanced to ensure stable flight characteristics, thus it would not be a practical permanent fix. It is however the most conventional repair and thus would require the least amount of recertification to get it back in the air. Once this is done the aircraft will be flown back to the manufacturing plant where it will have a new fuselage barrel created in order to permanently fix the aircraft and return it to its full performance specifications. With this type of repair, the aircraft would need a "ferry flight for repairs, alterations, maintenance or storage" flight permit certification, instead of a standard airworthiness certificate [28]. This would decrease the certification time and costs as this certificate only requires certification for one flight without passengers[29].

The second system concept is based on BPRS and consists of creating a permanent repair. In order for this repair to work, a patch needs to be created that closely resembles the original fuselage section in terms of its structural strength. This means creating a new ATL patch and bonding it to the ribs as was done with the rest of the fuselage. The bonding however will have to be more robust to connect it with the undamaged fuselage in order to ensure proper load flow through the whole fuselage structure. With this and the addition of repairing the damaged rib sections the weight of the aircraft might be different that the original design. If this is the case permanent ballast weights will then need to be installed. This will result in a permanent decrease in the maximum payload capacity of the aircraft. 


\section{Chapter 5 Concept Models}

In order to further explore these two system concepts, two models were created in CATIA V5. Due to the lack of available knowledge of the material or the dimensions of the fuselage structure some assumptions were made. Firstly the design itself is roughly the size and shape of the 787 main fuselage barrel, complete with stringers that run the length of the cylinder. While the radius and length are accurate to the real world fuselage dimensions the stringers themselves are not; this was done to simplify the analysis and create and "over engineered" version of the model due to the unknowns. Secondly the material was chosen to be the stock epoxy that is in the CATIA database, which has a density of $1300 \mathrm{~kg} / \mathrm{m}^{3}$, a Poisson ratio of 0.37 and a Young modulus of $3 \mathrm{E}^{9} \mathrm{~N} / \mathrm{m}^{2}$. Thus the stress analysis performed was merely performed to show visually what the concepts could potentially look like and the stress concentrations on them. Figure 10 shows the dimensions of the designed fuselage barrel and damaged section. For simplicity the design consists of a cylindrical fuselage section, where the damaged section on the top port side of the aircraft is already cut out. 


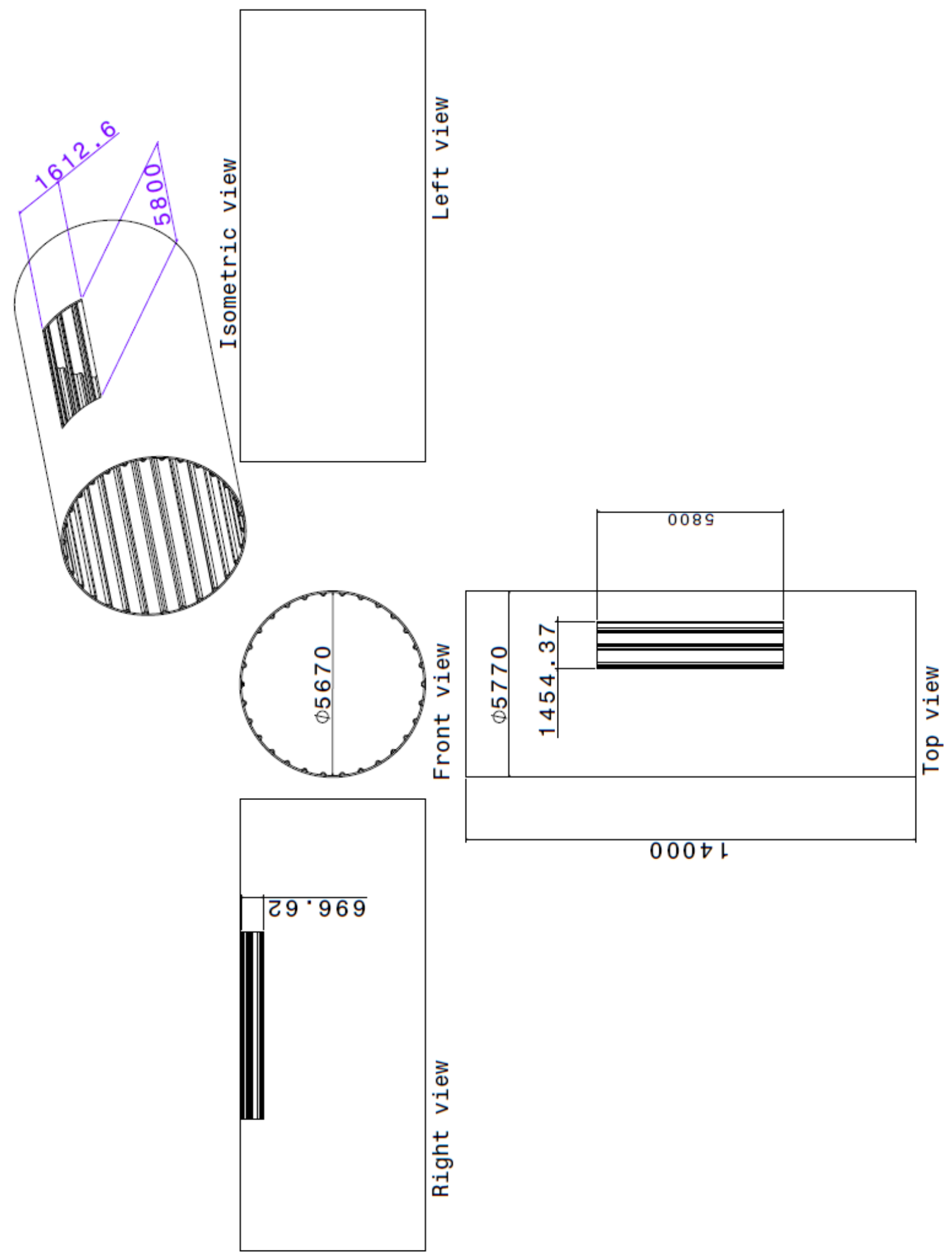

Figure 10 - Dimensions of the Damaged Fuselage Section (mm) 
The system concepts consisted of other assumptions for simplicity and due to lack of available knowledge surrounding the practical and virtual analysis process of repairing such a large scale composite structure. For the bonded permanent repair the model consisted of a larger patch of material to cover the damaged area. This was done to represent the extra material required to safely restore the damaged section to the original strength, and even make it stronger due to the unknowns of bonded repair on this large of a scale. Figure 11 and Figure 12 show the dimensions of the bonded patch geometry.

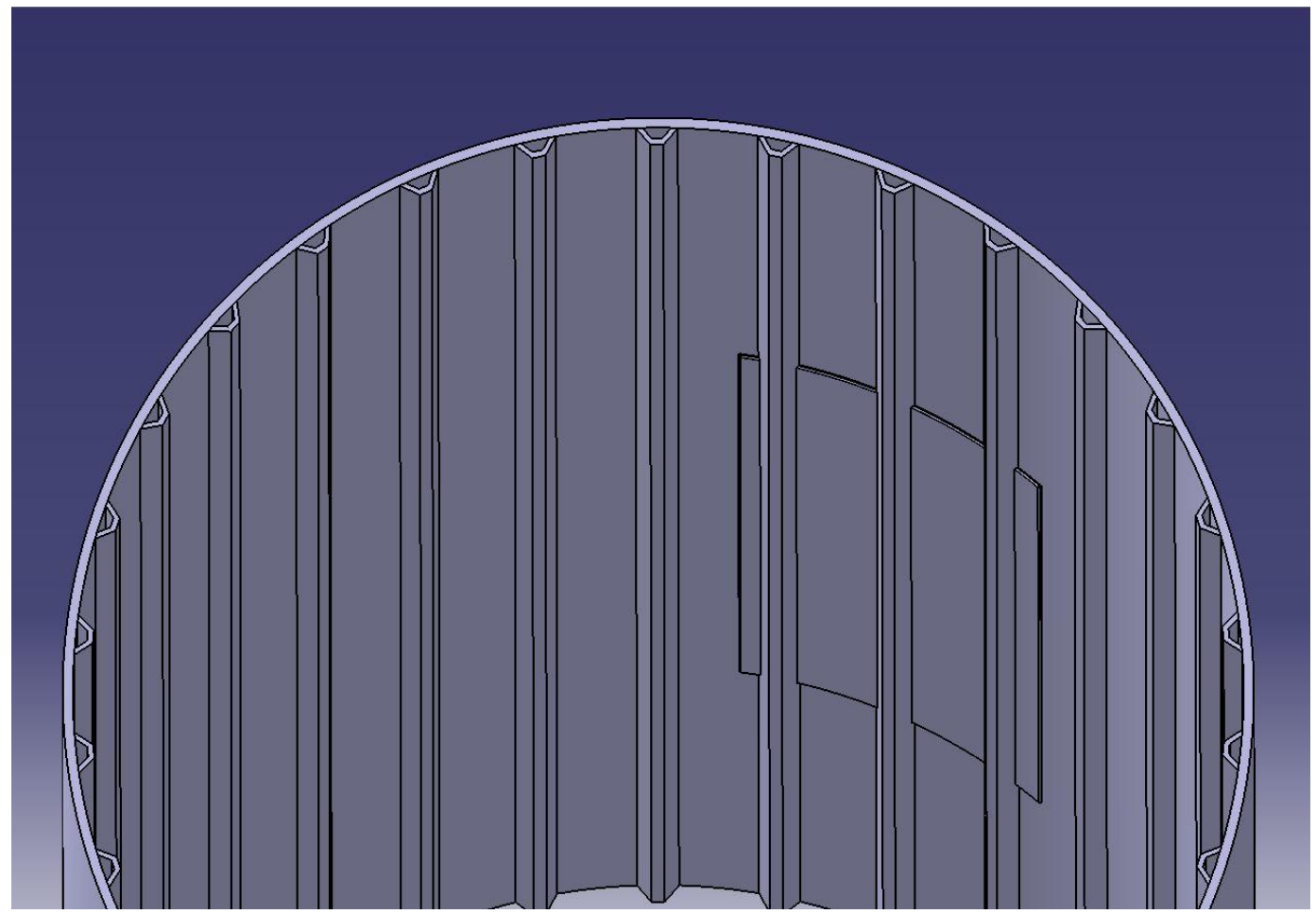

Figure 11 - Interior of the Fuselage Barrel Section Showing the Bonded Patch 


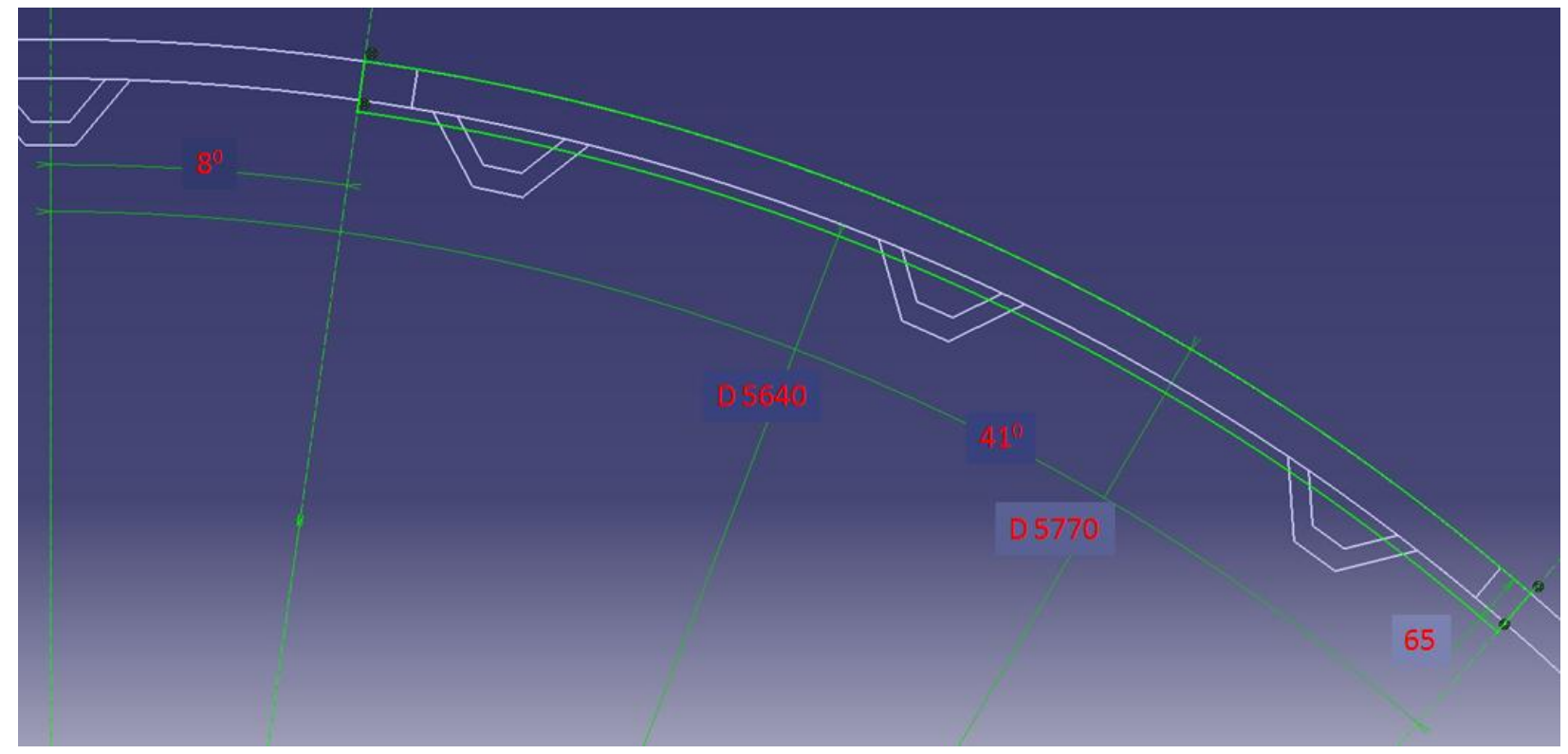

Figure 12 - Dimensions for the Bonded Patch (mm)

The bolted repair consisted of a lighter weight patch where the damaged section was and additional stringers on the interior dorsal section of the fuselage for added strength and rigidity. Figure 13 and Figure 14 show the dimensions and geometry of the stringers used to reinforce the bolted repair.

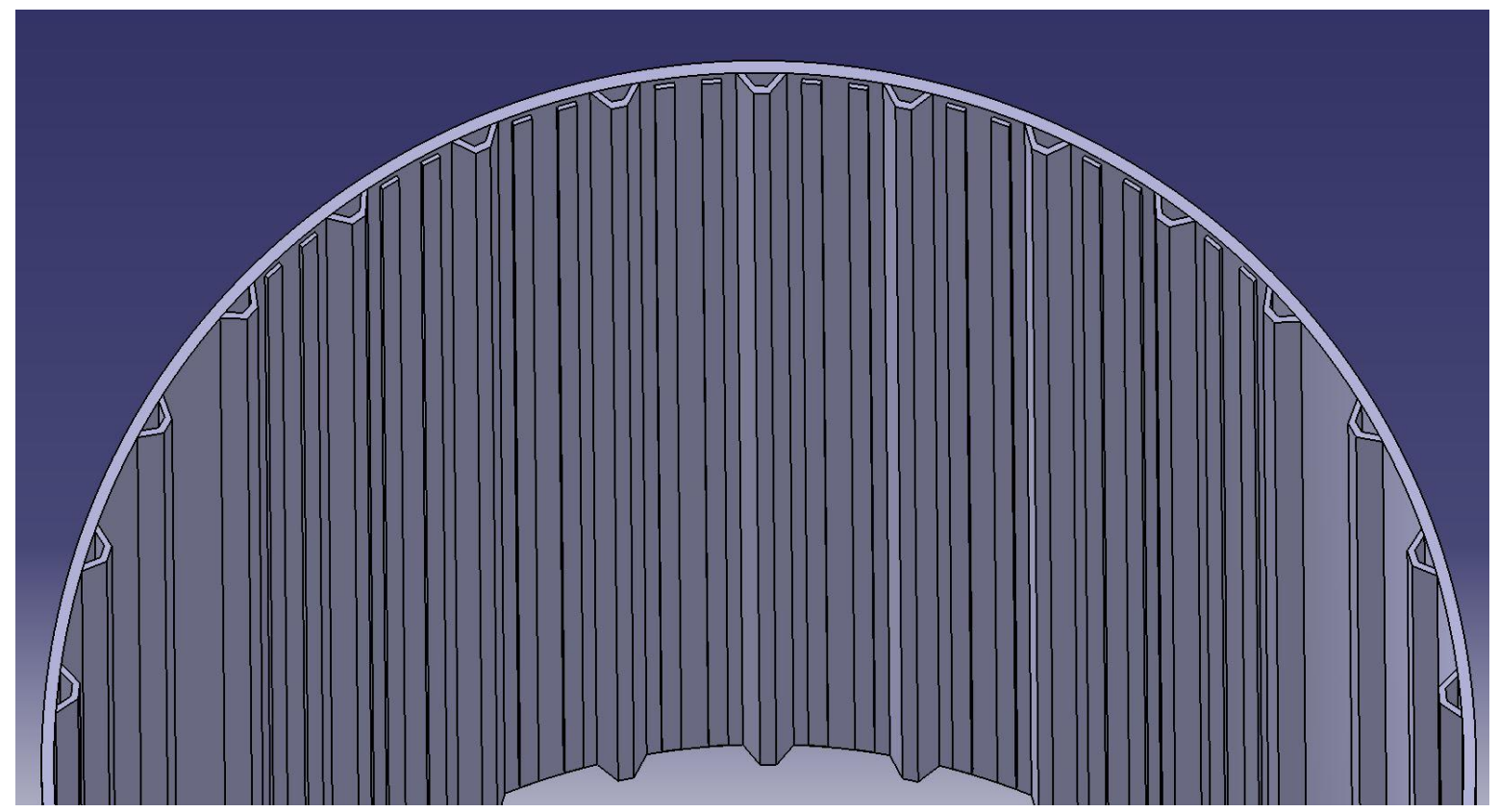

Figure 13 - Fuselage Barrel Interior with the Additional Stringers on the Bolted Repair 


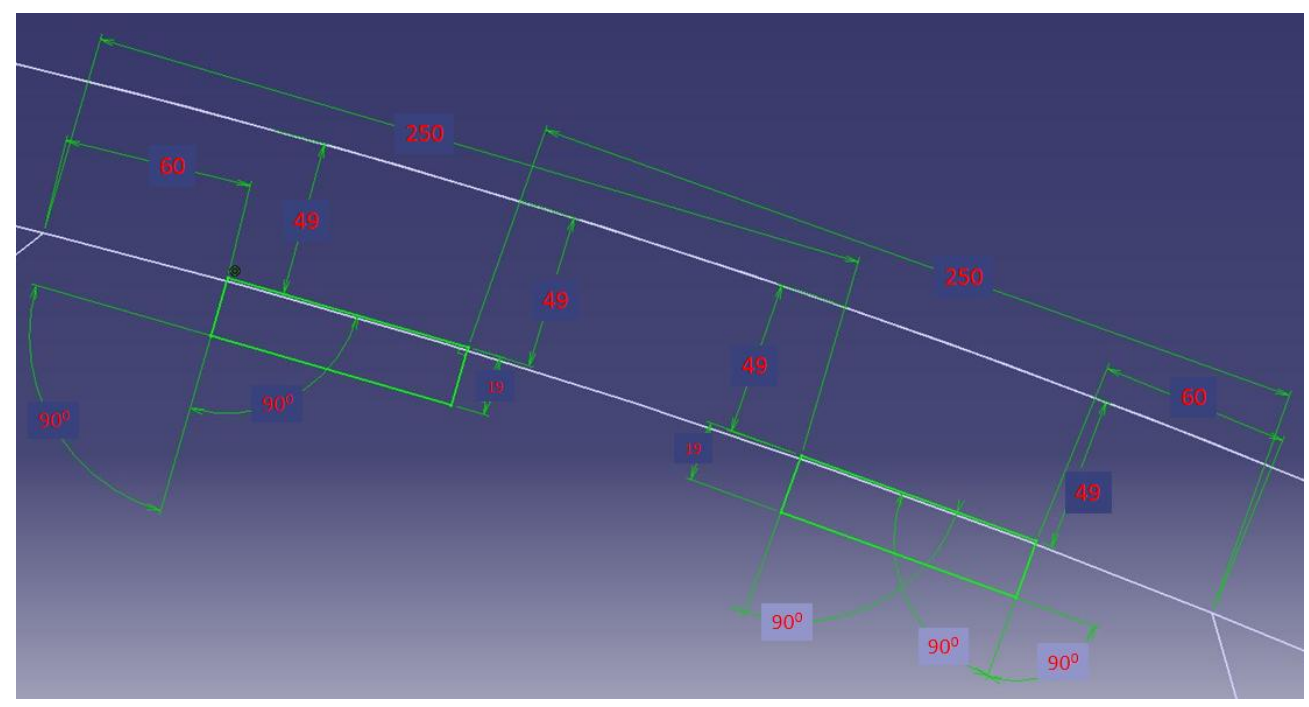

Figure 14 - Dimensions for the Additional Stringers (mm)

Figure 15 shows the holes implemented into the bolted patch to more accurately represent lighter, less robust patch applied in this scenario, compared to the bonded scenario where an ATL patch is used.

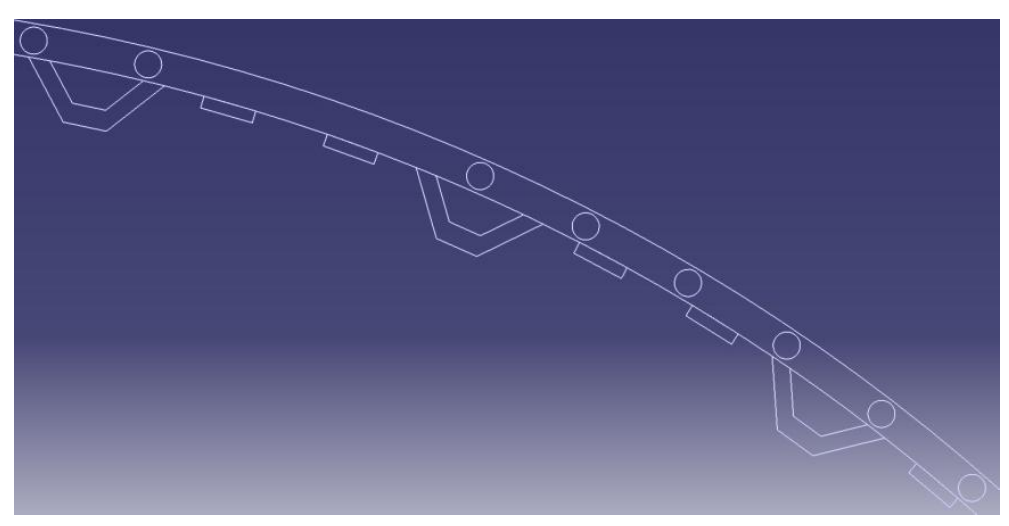

Figure 15 - Holes used to Lighten and Weaken the Bolted Patch Repair

There is also the question of weight and balance when it comes to these new designs. A brief analysis can be done of the weights and center of gravity of each of these designs. This is done to just get a sense of how these designs would be in the real world. 
Table 1 - Weights and Center of Gravity for Each of the Test Models

\begin{tabular}{lrrrr}
\hline & Clean & Damaged & Bonded & \multicolumn{1}{c}{ Bolted } \\
\hline Volume $\left(\mathbf{m}^{\mathbf{3}}\right)$ & 15.187 & 14.717 & 15.313 & 15.449 \\
Area $\left(\mathbf{m}^{\mathbf{2}}\right)$ & 730.934 & 712.864 & 727.464 & 738.928 \\
Mass $(\mathbf{k g})$ & 19743.467 & 19132.032 & 19906.767 & 20083.54 \\
Center of gravity $\mathbf{x}(\mathbf{m m})$ & 0 & 0 & 0 & 0 \\
Center of gravity $\mathbf{y}(\mathbf{m m})$ & 0 & -39.000 & 9.513 & -4.694 \\
Center of gravity $\mathbf{z}(\mathbf{m m})$ & 0 & -81.315 & 20.810 & 42.530 \\
\hline
\end{tabular}

From the table it can be seen that both the bolted and bonded designs are heavier than the original, however the molted is slightly higher. Also while the bonded model has a center of gravity closer to the port side of the aircraft than the bolted model, the bolted design has a much higher center of gravity. The difference between the two however is that the bolted design is meant to be temporary, having to achieve only one ferry flight for repairs, thus the rebalancing can be done easily with ballast tanks and removed once the permanent fix is achieved. The bonded repair however is permanent, and as such will need ballasts to re-balance the airframe for the remainder of its service life.

\subsection{Stress Analysis}

The finite element stress analysis was completed in CATIA V5. The loading condition consisted of clamping one end of the fuselage cylinder and applying a load of $600 \mathrm{kN}$ to the other. This represents a real world loading case scenario that the aircraft could experience [30]. Figure 16 shows the boundary conditions of the stress analysis model. 


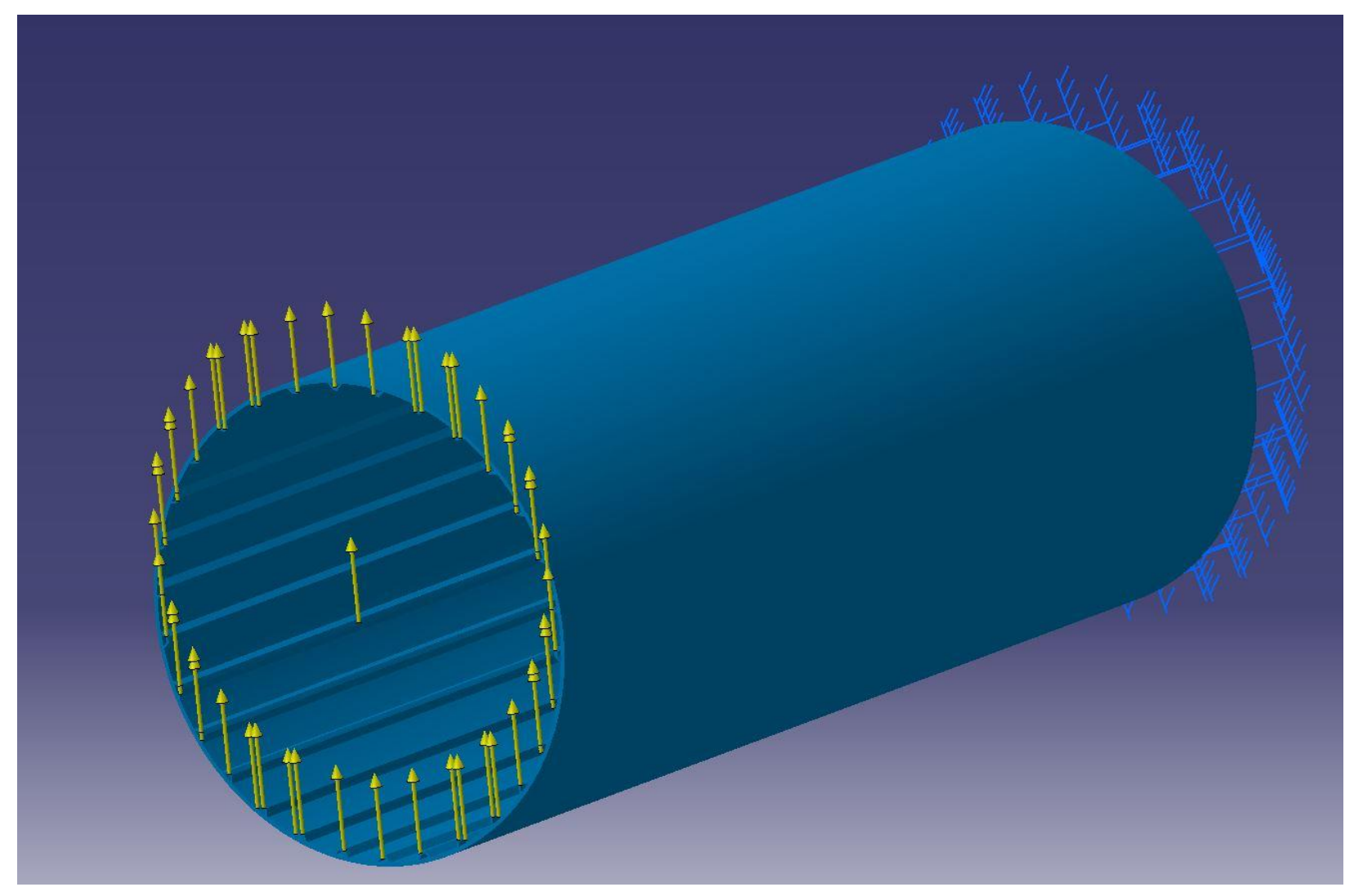

Figure 16 - Stress Analysis Loading Conditions

While the model and loading conditions are simplified this was done solely due to lack of available knowledge regarding the composite material, shape of the fuselage and the loading the aircraft experiences. All of the different models where loaded exactly the same way. Similarly all of the test models were meshed the same way in CATIA. Figure 17 shows a close up view of the mesh on one of the stringers as well as the main properties of the mesh which are that a linear OCTREE tetrahedron mesh was used with a mesh size of $50 \mathrm{~mm}$ and an absolute sag of $5 \mathrm{~mm}$. Table 2 displays the additional information about the mesh used for analysis. 


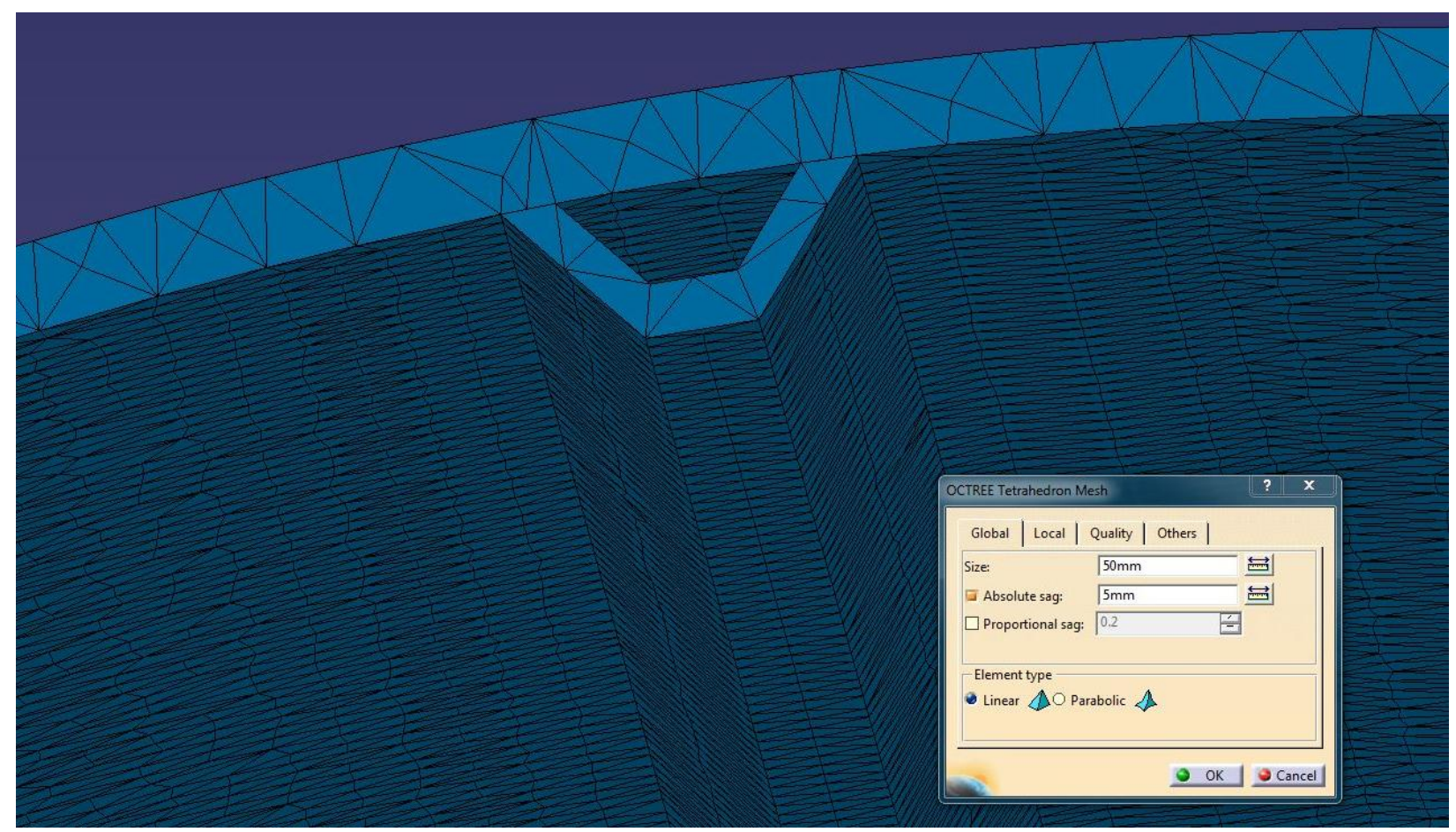

Figure 17 - Finite Element Mesh

Table 2 - Mesh Characteristics

\begin{tabular}{ll}
\hline Characteristic & Value \\
\hline Mesh Type & OCTREE Tetrahedron \\
\hline Element Type & Linear \\
Mesh Size & $50 \mathrm{~mm}$ \\
Absolute Sag & $5 \mathrm{~mm}$ \\
Geometry Size Limit & $0.1 \mathrm{~mm}$ \\
Mesh Edges Suppression & 0.2 \\
Min. Size for Sag Specs & $109.377 \mathrm{~mm}$ \\
Jacobian & 0.3 \\
Warp & 60 \\
\hline
\end{tabular}

Once the analysis was completed, the results were documented in the following figures. These results are not meant to act as direct comparisons or designs for real world scenarios, but rather proof of concepts for stress concentrations and design principles. Firstly the undamaged stock section was tested; it will be known as the "clean" configuration. Figure 18 shows the VonMises stress values, as well as the stress concentrations and the deformation of the fuselage section. 


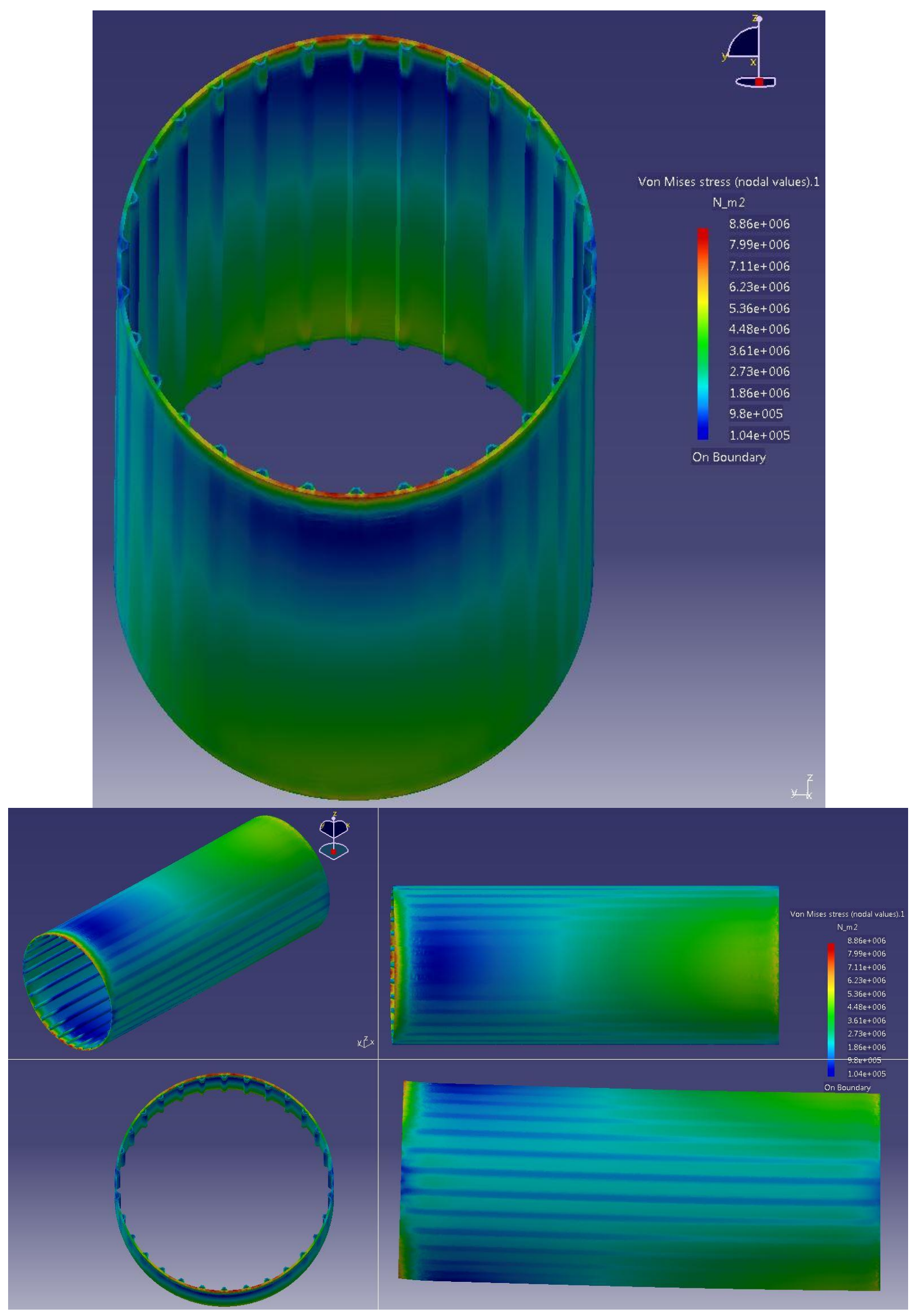

Figure 18 - "Clean" Configuration Stress Analysis 
As expected the highest points of stress are where at the point where the force was applied, as well as the top and bottom of the barrel at the two ends. Figure 19 shows the damaged fuselage barrel stress analysis, showcasing the high levels of stress concentrated on the corners of the damaged section, as well as the high degree of deformation throughout.

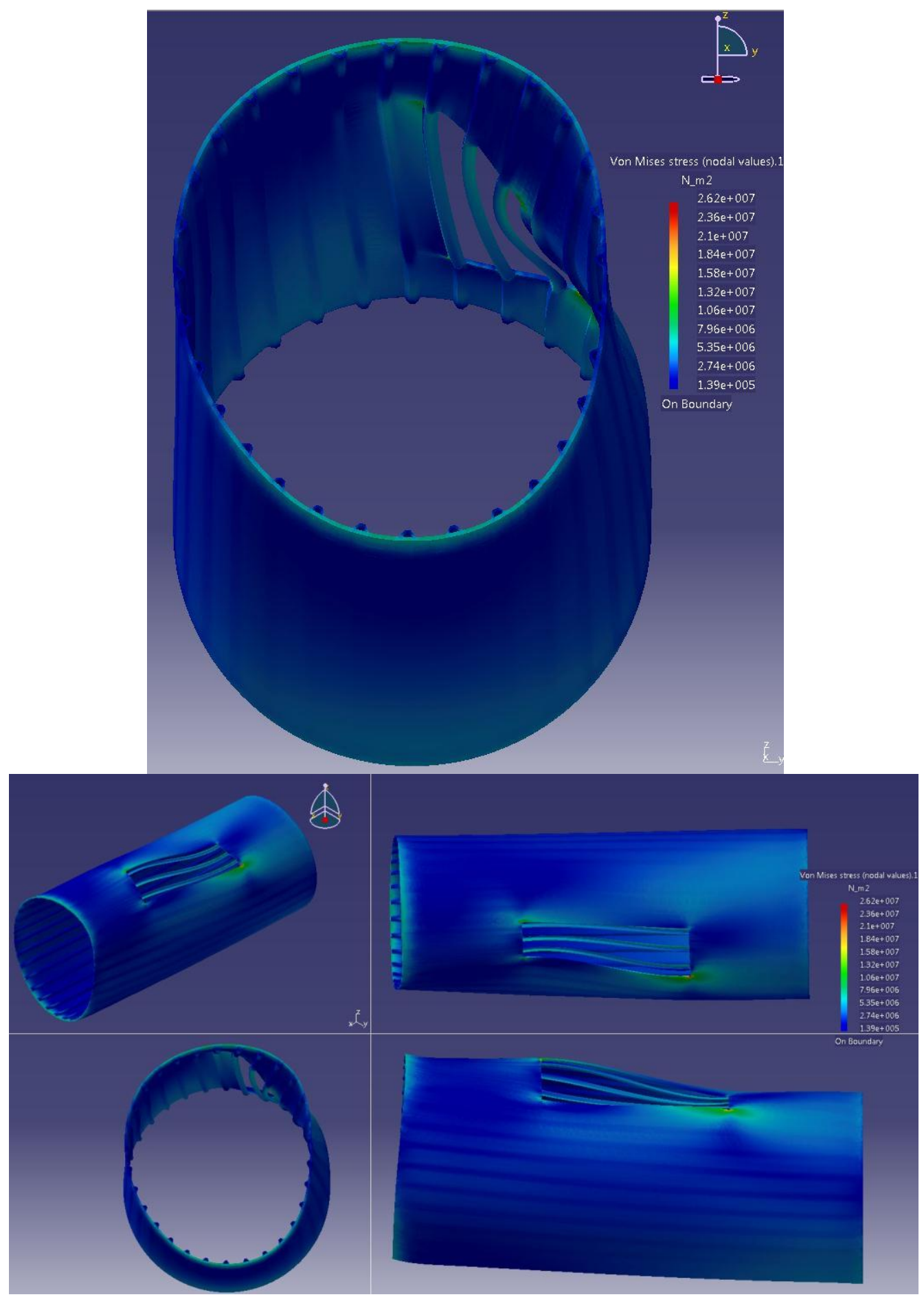

Figure 19 - Damaged Configuration Stress Analysis 
Figure 20 shows the stress analysis for the bonded configuration. Here it can be seen that the stress distribution very closely resembles that of the clean configuration, however there are slight differences. For example the maximum Von-Mises stress has decreased from $8.86 \mathrm{E}^{6}$ to $8.70 \mathrm{E}^{6} \mathrm{~N} / \mathrm{m}^{2}$, and there is a slight reduction in stress in the around the patch itself.

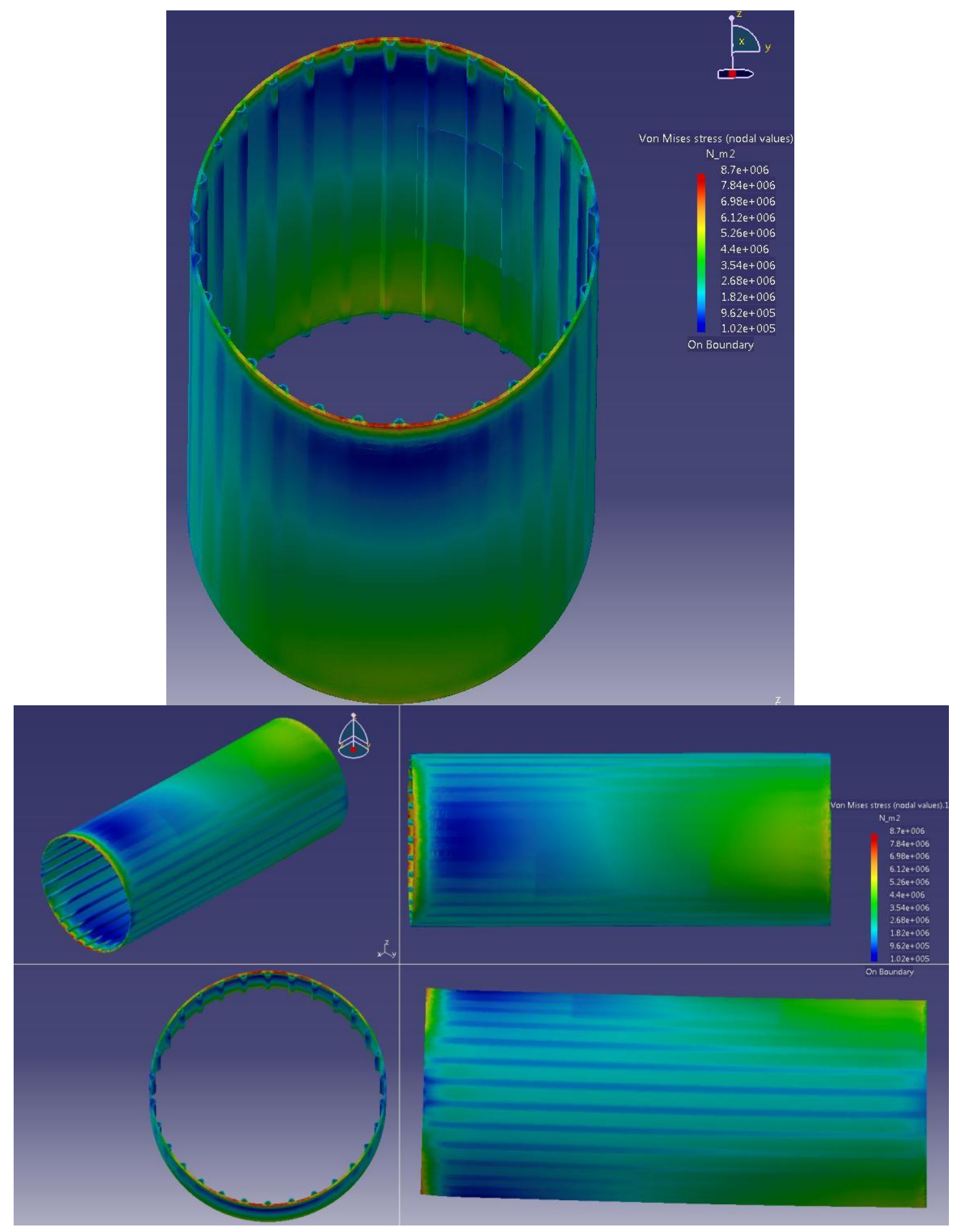

Figure 20 - Bonded Configuration Stress Analysis 
Figure 21 shows the stress analysis for the bolted repair. On this model it can be seen that while the maximum stress is less than the clean configuration, it is still slightly higher than the bonded repair at $8.77 \mathrm{E}^{6} \mathrm{~N} / \mathrm{m}^{2}$. From all of the tests on all of these models it can be seen that both patch methods are effective at restoring the structural strength to be stronger than the original.

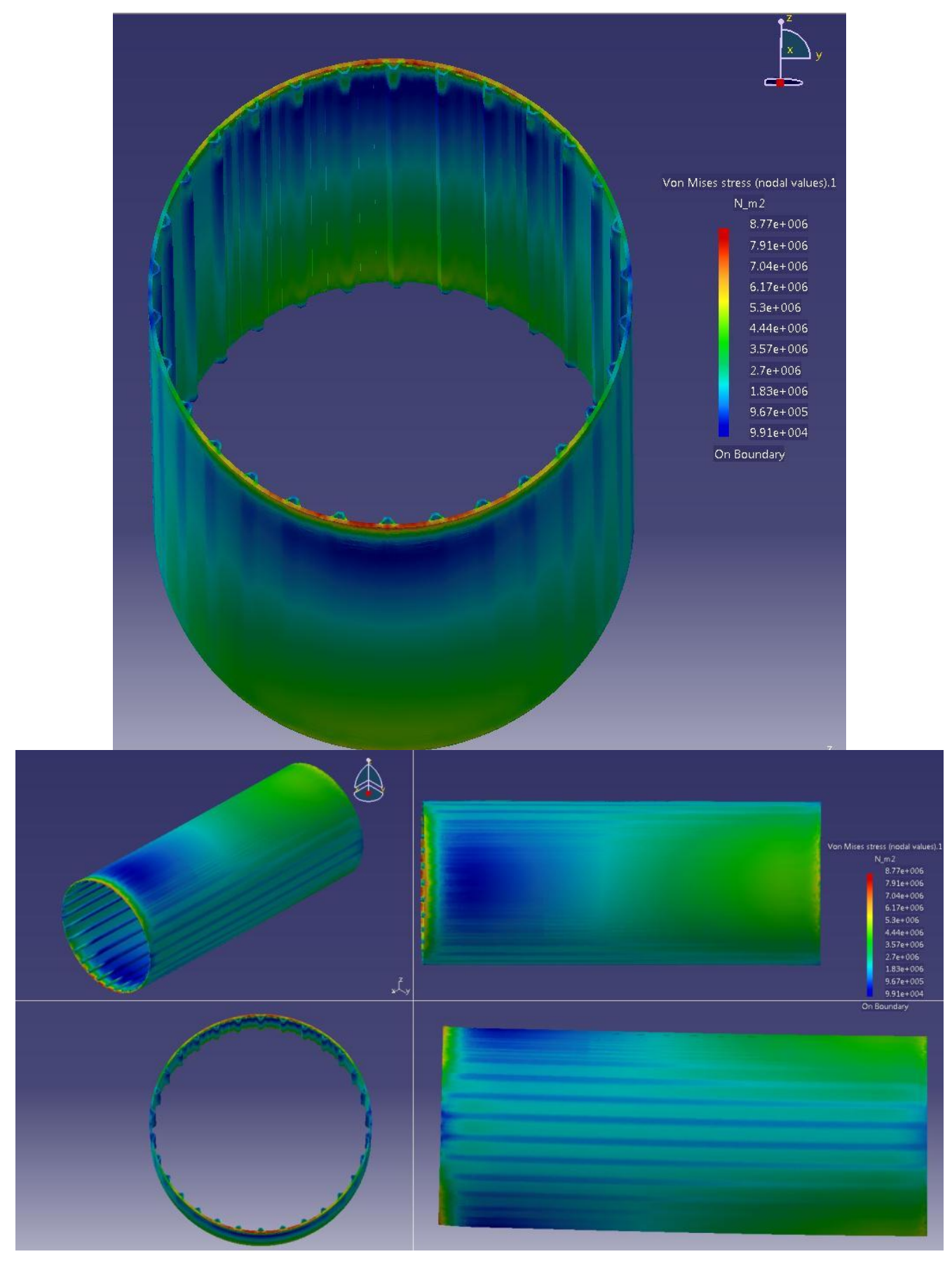

Figure 21 - Bolted Configuration Stress Analysis 


\subsection{Validation}

While the results seen above can give a rough estimation of the effects of loading on the damaged section and subsequent repair method concepts, these results have not been verified. Continuing research will still need to be done, not only on the testing of these structures, but the evaluation methods themselves. It would prove very beneficial if a real world test of these conceptual structure designs and the damaged section. Perhaps this could be done by using a genuine 787 fuselage structure as the test subject and applying real world flight condition loads to the structure. In doing this it would ensure the most accurate results from the structural tests of the different concepts as to which one would be the best suited structure for the repair. The information gained from this type of real world experimentation validation and comparison between different types of composite repair on a fuselage of this scope could be invaluable and significantly advance the understanding of how these composites react when repairs are completed on them.

During these experiments, or possibly a separate experiment that could take place is the evaluation of several or all of the NDE devices and techniques in order to accurately, easily and thus more effectively be able to detect the damage of a composite structure that has been exposed to thermal stress. This evaluation knowledge would extend beyond simply detecting where, and how large the damaged area is. If given enough research these experiments could also potentially be able to precisely predict the extent to which the physical properties of the structure have been compromised. This would be considered a significant undertaking however, because such factors as material configuration, which consists of matrix and fiber composition and percentage as well as fiber orientation, and structural configuration will both need to be taken into account in order to obtain result accurate enough for proper prediction of the change in structure properties. 


\section{Chapter 6 Conclusion}

The inclusion of fiber composites on major structural components of aircraft is relatively new. Because of this very little is known about certain service life fatigue and damage scenarios such as thermal stress and fire damage on composite structures. While the configuration of compose fuselage structures differ greatly between the few aircraft that use them, there is no current standard for the repair of the heat damaged section. From literature there have been some examples of different structures that, in theory could be used as patch repairs, and there are different methods theorized as to the process in which to install them. Additionally there have been many different detection and NDE methods in which to determine the size and extent of the damage sustained by a composite structure that has been exposed to excessive thermal stress.

From these lessons learned in the literature reviewed, a conceptual system design can was created which outlines the possible processes taken to complete such repairs. From this it was determined that there could be two types of possible that would be the most viable repair scenarios. One scenario involves creating a temporary patch repair until the aircraft can be flown back to the OEM manufacturing facility, where the aircraft will have the whole damaged section replaced. The second scenario involves creating a permanent repair patch which is cut from a new barrel section. While this type of repair would cost less the amount of time to analyze the damage and certify the patch could be higher than the other scenario. The first scenario will ultimately cost more due to the addition of the temporary patch; however the finished repair will bring the aircraft back to its undamaged factory specifications. In terms of the finite element and model analysis it was shown that a model could be made to restore the damaged section to its original structural strength. More importantly, these concepts showed the proof of concept that 
these configurations did not add any undue stress concentrations to the fuselage structural. Also shown in these models was the problem of added weight and an unbalanced center of gravity. By adding these patches onto the airframe to restore its structural strength, weight is added to the aircraft in places which would divert the aircraft fuselage's center of gravity off from its center. This would mean that in order to obtain the original flight characteristics of the undamaged aircraft ballast tanks would need to be implemented to balance the aircraft. This would increase the weight further which would take away, if only slightly, from the main advantage of utilizing a composite airframe in the first place, that is the decreased weight over metal. Alternatively, and what is ultimately suggested by this report, a temporary repair could be implemented on the aircraft until it could have the entire damaged barrel section removed and have a new one installed that would restore it to factory specifications. Ultimately experimental validation is needed in order for these structures and testing methods to be accurately proven in real world conditions. Once this is done however, the applications that could benefit from this invaluable knowledge of composite damage detection and repair would be virtually endless. 


\section{Chapter 7 Bibliography}

[1] A. P. Mouritz and A. G. Gibson, Fire Properties of Polymer Composite Materials, Dordrecht: Springer, 2006.

[2] G. Marsh, "The challenge of composite fuselage repair," REINFORCEDplastics, pp. 30 - 36, 2012.

[3] G. J. Czarnecki, E. R. Ripberger, R. J. Meilunas, W. Milan and J. P. Haas, "Thermal Degradation of Composites," in Structural Dynamics and Materials Conference, Denver, 2011.

[4] A. P. MOURITZ, "Fire resistance of aircraft composite laminates," JOURNAL OF MATERIALS SCIENCE LETTERS, vol. 22, p. $1507-1509,2003$.

[5] Federal Aviation Administration, FAR 23.573 Damage tolerance and fatigue evaluation of structure., 2014.

[6] S. Wilhelm, "Experts ponder how Ethiopian 787 can be repaired," Puget Sound Busness Journal, 2013.

[7] Boeing, "787 Aircraft Rescue \& Firefighting Composite Structure," Boeing, 2013.

[8] G. Arnold, "A morning at Boeing," 9 April 2009. [Online]. Available: http://geoffarnold.com/?p=3124.

[9] M. Oneal, "Boeing Bets Big On A Plastic Plane: 7E7 must soar for company to challenge Europeans' supremacy," Chicago Tribune, 12 January 2005.

[10] G. Norris, "Ethiopian's Boeing 787 Fuselage Repair Passes Halfway Stage," Aviation Week, 26 November 2013.

[11] T. Curtis, "Update on 787 fire in London plus radio interview on 777 crash," 17 July 2013. [Online]. Available: http://www.airsafenews.com/2013/07/update-on-787-fire-in-london-plus-radio.html.

[12] J. Sloan, "Following latest 787 fire, time to repair carbon fiber fuselage," Composites World, July 2013.

[13] Renfrewshire Council; Scottish Enterprise Renfrewshire; BAA Glasgow, "Aircraft Maintenance Repair and Overhaul Market Study," STRAIR, Glasgow, 2007.

[14] S. E. H. a. T. E. M. Steven M. Huybrechts, "Grid stiffened structures: a survey of fabrication, analysis and design methods," Proceedings of the 12th International Conference on Composite Materials, 
July 1999.

[15] D. Han and S. W. Tsai, "Interlocked Composite Grids Design and Manufacturing," Department of Aeronautics and Astronautics, Stanford University, Stanford, 2002.

[16] The Boeing Company, "Boeing Image Gallery," 11 January 2005. [Online]. Available: http://www.boeing.com/boeing/companyoffices/gallery/images/commercial/787/k63211-1.page. [Accessed 20 June 2014].

[17] Department of Defense, COMPOSITE MATERIALS HANDBOOK VOLUME 3: POLYMER MATRIX COMPOSITES MATERIALS USAGE, DESIGN, AND ANALYSIS, Washington, DC: U.S. Department of Defense, 1997.

[18] CRC Press LLC, "Filament Winding: Definition," CRC Press LLC, Boca Raton, 1959.

[19] S. Peters, Composite Filament Winding, Cleveland: ASM International, 2011.

[20] M. Velmurugan, R. M. Buragohain and a. R. Velmurugan, "Optimal Design of Filament Wound GridStiffened Composite Cylindrical Structures," Defence Science Journal, vol. 61, no. 1, pp. 88 - 94, January 2011.

[21] S. M. Huybrechts, S. E. Hahn and T. E. Meink, "Grid Stiffened Structures: A Survey of Fabrication, Analysis and Design Methods," in International Conference on Composite Materials (ICCM), 1999.

[22] EngineBLock, "How Is Boeing 787 Dreamliner Composite Fuselage Constructed," Gizmo Crazed, 13 October 2011. [Online]. Available: http://www.gizmocrazed.com/2011/10/how-is-boeing-787dreamliner-composite-fuselage-constructed-images/. [Accessed July 2014].

[23] J. Seelenbinder, "Composite heat damage measurement using the handheld Algient 4100," Agilent Technologies, 2011.

[24] Ł. K. M. K. A. L. M. S. P. S. a. J. B. Krzysztof Dragan, "DAMAGE DETECTION AND SIZE QUANTIFICATION OF FML WITH THE USE OF NDE," Fatigue of Aircraft Structures, vol. 1, no. 1, pp. 5 - 9, 2012.

[25] J. L. Kinsey, "LASER-INDUCED FLUORESCENCE," Annual Review of Physical Chemestry, vol. 28, pp. $349-372,1977$.

[26] S. M. Shepard, "Flash Thermography of Aerospace Composites," in Conferencia Panamericana de END, Buenos Aires, 2007.

[27] M. Tarin and R. Rotolante, "NDT in Composite Materials with Flash, Transient, and Lock-in Thermography," MoviTHERM, Inc., Wilsonville, 2011. 
[28] U. S. Department of Transportation, APPLICATION FOR U.S. AIRWORTHINESS CERTIFICATE, 2013.

[29] Federal Aviation Administration, Special Flight Permits, 2014.

[30] M. v. Tooren and L. Krakers, "Multi-disciplinary Design of Aircraft Fuselage Structures," AIAA Aerospace Science Meeting, vol. 14, no. Collection of Technical Papers 45th, pp. 9419 - 9431, 2007.

[31] J. Hale, "787 Design for Maintainability," 2008.

[32] C. Drew and J. Mouawad, "Fixing 787's fuselage proves a challenge," International Herald Tribune [Paris], pp. 15 - 18, 31 July 2013.

[33] Federal Aviation Administration, "Past Experiences and Future Trends for Composite Aircraft Structure," in Montana State University Seminar, Bozeman, 2009.

[34] U. S. Government Accountability Office, "Status of FAA's Actions to Oversee the Safety of Composite Airplanes," U. S. GAO, 2011.

[35] Boeing, "787 Aircraft Rescue \& Firefighting Composite Structure," Boeing, 2013.

[36] S. H. Huybrechts, T. E. Meink, P. M. Wegner and J. M. Ganley, "Manufacturing Theory for Advanced Grid Stiffened Structures," Composites, vol. 33, pp. 155 - 161, 2002.

[37] R. R. V. a. L. W. R. Ambur D. Reddy, "Continuous Filament Wound Composite Concepts for Aircraft Fuselage Structures," Journal of Aircraft, vol. 22, no. 3, pp. 249 - 255, 1985.

[38] C. H. S.-G. K. a. C.-U. K. Jae-Sung Park, "Analysis of Filament Wound Composite Structures Considering the Change of Winding Angles Through the Thickness Direction," Composite Structures, pp. 63 - 71, 2002. 